Chan, T. M. and Gardner, L. (2008). Bending strength of hot-rolled elliptical hollow sections. Journal of Constructional Steel Research. 64(9), 971-986.

\title{
Bending strength of hot-rolled elliptical hollow sections
}

\author{
T. M. Chan ${ }^{1}$ and L. Gardner ${ }^{2}$ \\ 1 Assistant Professor in Structural Engineering, Division of Civil and Mechanical Engineering, School of \\ Engineering, University of Warwick, Coventry, CV4 7AL, UK. Email: T.m.chan@warwick.ac.uk \\ ${ }^{2}$ Senior Lecturer in Structural Engineering, Department of Civil and Environmental Engineering, South Kensington \\ Campus, Imperial College London, SW7 2AZ, UK. Email: Leroy.gardner@imperial.ac.uk
}

\begin{abstract}
The recent emergence of hot-rolled elliptical hollow sections (EHS) within the construction industry has attracted considerable interest from structural engineers and architects. Comprehensive structural design rules are now required to facilitate their wider application. This paper focuses on the bending strength of hot-rolled elliptical hollow sections; the results of detailed experimental and numerical studies are presented and structural design rules for EHS in bending about the major and minor axes are proposed. A total of 18 in-plane bending tests in three-point and four-point configurations have been performed. All tested specimens had an aspect ratio of two. Full moment-rotation and moment-curvature histories were derived, including into the post-ultimate range. The experimental results were replicated by means of non-linear numerical modelling. Following careful validation of the models, parametric studies were performed to assess the structural response of EHS over a wider range of aspect ratios (between one (CHS) and three) and cross-section slendernessess. For design, cross-section slenderness parameters have been proposed and a set of classification limits in harmony with those given in Eurocode 3 for circular hollow sections (CHS) has been derived. A new Class 3 limit has also been proposed for both EHS and CHS. An interim effective section modulus
\end{abstract}


formula for Class 4 (slender) elliptical hollow sections based on BS 5950-1 has also been developed. Further investigation into effective section modulus formulations is currently underway.

Keywords: Bending; cross-section classification; elliptical hollow sections; flexure; laboratory testing; numerical modelling; oval hollow sections; slenderness limits; steel structures

\section{Introduction}

Tubular members are widely used in a range of engineering applications. Their closed nature brings structural efficiency, high torsional stiffness and aesthetic appearance; it also effectively offers permanent formwork enabling increased load bearing capacity to be achieved through concrete filling. To date, square, rectangular and circular hollow sections have been the dominant tubular products. However, elliptical hollow sections (EHS) are now also available as hot-rolled products of structural proportions, and a number of projects employing EHS, such as the Terminal 5 building at Heathrow Airport in London [1], have already emerged [2]. Together with a streamlined appearance, EHS also have differing major and minor axes structural properties allowing the sections to be orientated to suit and most effectively resist the applied loading.

To facilitate the wider application of elliptical hollow sections, comprehensive structural design rules verified against test data are required. This paper addresses the bending strength of elliptical hollow sections, and provides the results of 18 in-plane bending tests ( 8 three-point bending and 10 four-point bending tests) together with extensive numerical results, 
complementing the previous findings of the authors [3]. All tested elliptical hollow sections had an aspect ratio of two and section sizes ranged from $400 \times 200$ up to $500 \times 250 \mathrm{~mm}$. The generated structural performance data have been used to establish relationships between cross-section slenderness and cross-section bending resistances and to develop cross-section classification limits. The results presented herein for bending have been used in conjunction with those attained for compression [4] to establish slenderness parameters and a system of cross-section classification limits for elliptical hollow sections [5].

The varying curvature of an elliptical hollow section (EHS) distinguishes it from other tubular sections, and leads to differing bending behaviour about the two principal axes. For bending about the minor (z-z) axis, the maximum compressive stress coincides with the point of maximum radius of curvature (the least stiff part of the cross-section), which can be shown to be $a^{2} / b$, where $a$ and $b$ are defined in Fig. 1 . Local buckling therefore initiates at this position. However, for bending about the major (y-y) axis, the maximum compressive stress coincides with the stiffest part of the cross-section (most resistant to local buckling), where the radius of curvature is as its minimum value and equal to $b^{2} / a$. The theoretical point of initiation of buckling can be deduced by optimising the function composed of the varying curvature expression and the elastic bending stress distribution and can be shown to exist at a distance of $0.42 \mathrm{a}$ from the end of the minor $(\mathrm{z}-\mathrm{z})$ axis. The corresponding radius of curvature is equal to $0.65 \mathrm{a}^{2} / \mathrm{b}$, which will be discussed in Section 4 .

The elastic and plastic moment capacities of an elliptical hollow section can be derived from fundamental engineering mechanics. The elastic moment capacity $\mathrm{Mel}_{\mathrm{el}}$ is defined by Eq. (1).

$$
\mathrm{M}_{\mathrm{el}}=\sigma_{\mathrm{y}} \mathrm{W}_{\mathrm{el}}
$$


where $\sigma_{\mathrm{y}}$ is the material yield stress and $\mathrm{W}_{\mathrm{el}}$ is the elastic section modulus. The exact elastic section moduli for bending about the major $(\mathrm{y}-\mathrm{y})$ and minor $(\mathrm{z}-\mathrm{z})$ axes, $\mathrm{W}_{\mathrm{el}, \mathrm{y}}$ and $\mathrm{W}_{\mathrm{el}, \mathrm{z}}$, for an EHS of constant thickness $\mathrm{t}$ can be obtained by integration along the circumference of the median-profile of the section to give Eqs (2) and (3), respectively.

$$
\begin{aligned}
& \mathrm{W}_{\mathrm{el}, \mathrm{y}}=\frac{\mathrm{I}_{\mathrm{y}}}{\mathrm{a}}=\frac{4 \mathrm{a}_{\mathrm{m}}{ }^{3} \mathrm{t}}{\mathrm{a}} \int_{0}^{\frac{\pi}{2}} \cos ^{2} \phi \sqrt{\sin ^{2} \phi+\frac{\mathrm{b}_{\mathrm{m}}{ }^{2}}{\mathrm{a}_{\mathrm{m}}{ }^{2}} \cos ^{2} \phi} \mathrm{d} \phi \\
& \mathrm{W}_{\mathrm{el}, \mathrm{z}}=\frac{\mathrm{I}_{\mathrm{z}}}{\mathrm{b}}=\frac{4 \mathrm{a}_{\mathrm{m}} \mathrm{b}_{\mathrm{m}}{ }^{2} \mathrm{t}}{\mathrm{b}} \int_{0}^{\frac{\pi}{2}} \sin ^{2} \phi \sqrt{\sin ^{2} \phi+\frac{\mathrm{b}_{\mathrm{m}}{ }^{2}}{\mathrm{a}_{\mathrm{m}}{ }^{2}} \cos ^{2} \phi} \mathrm{d} \phi
\end{aligned}
$$

where $\mathrm{I}_{\mathrm{y}}$ and $\mathrm{I}_{\mathrm{z}}$ are the second moments of area about the major axis and minor axis respectively, $a_{m}=(2 a-t) / 2, b_{m}=(2 b-t) / 2$ and $\phi$ is the angle for each element measured from the $z-z$ axis, as shown in Fig. 1.

Similarly, the plastic moment capacity $\mathrm{M}_{\mathrm{pl}}$ is defined by Eq. (4).

$$
\mathrm{M}_{\mathrm{pl}}=\sigma_{\mathrm{y}} \mathrm{W}_{\mathrm{pl}}
$$

where $\mathrm{W}_{\mathrm{pl}}$ is the plastic section modulus and can be evaluated exactly by Eqs (5) and (6) for bending about the major (y-y) and minor (z-z) axes, respectively.

$$
\mathrm{W}_{\mathrm{pl}, \mathrm{y}}=4 \mathrm{a}_{\mathrm{m}}{ }^{2} \mathrm{t} \int_{0}^{\frac{\pi}{2}} \cos \phi \sqrt{\sin ^{2} \phi+\frac{\mathrm{b}_{\mathrm{m}}{ }^{2}}{\mathrm{a}_{\mathrm{m}}{ }^{2}} \cos ^{2} \phi} d \phi
$$




$$
\mathrm{W}_{\mathrm{pl}, \mathrm{z}}=4 \mathrm{a}_{\mathrm{m}} \mathrm{b}_{\mathrm{m}} \mathrm{t} \int_{0}^{\frac{\pi}{2}} \sin \phi \sqrt{\sin ^{2} \phi+\frac{\mathrm{b}_{\mathrm{m}}{ }^{2}}{\mathrm{a}_{\mathrm{m}}{ }^{2}} \cos ^{2} \phi} d \phi
$$

For the practical range of EHS, the average shape factor $\left(\mathrm{W}_{\mathrm{pl}} / \mathrm{W}_{\mathrm{el}}\right)$ based upon the aforementioned formulae is about 1.40 for bending about the major axis and 1.30 for bending about the minor axis. Simpler, approximate formulae are also provided in EN 10210-2 (2006) [6] for the determination of elastic and plastic section moduli. For the current range of EHS, these simpler formulae have been shown to underestimate the section modulii and the maximum deviation of those simpler formulae from the exact solutions of Eqs (2), (3), (5) and (6) is about

4\%. For accuracy, it is therefore recommended that Eqs (2), (3), (5) and (6) be adopted for the determination of the cross-section properties of an EHS, and this approach has been used throughout this paper, in line with the approach adopted in [4].

\section{Experimental study}

A comprehensive full-scale laboratory testing programme on EHS (grade S355), manufactured by Corus Tubes [7], was conducted at Imperial College London. The test programme comprised a total of 12 material tensile coupon tests and 18 in-plane bending tests.

\subsection{Tensile coupon tests}

Material tensile coupon tests were performed to determine the engineering stress-strain response of the material for each of the tested section sizes. The resulting material properties were used in the analysis of the bending test results and to facilitate numerical simulations of the test specimens. Full details of the tensile tests have been reported in [4], whilst a summary of the test results is given in Table 1 of this paper. 


\subsection{Bending tests}

Two principal symmetric testing configurations - four-point bending and three-point bending were employed. The primary aim of adopting these two bending configurations was to investigate the cross-section response under constant moment (four-point bending tests) and a moment gradient (three-point bending tests). In the four-point bending tests, the beam was of span $4.5 \mathrm{~m}$ while for the three-point bending tests, the span was $3 \mathrm{~m}$. This provided a consistent length of $1.5 \mathrm{~m}$ between the end support and the loading point. These two statically determinate configurations provide fundamental information, which may be used to simplify the analysis of redundant structures $[8,9]$. A total of 18 in-plane bending tests were conducted. Full momentcurvature and moment-rotation histories were derived for the four-point bending and three-point bending tests respectively.

\subsubsection{Four-point bending tests}

The objective of adopting this arrangement was to establish a relationship between cross-section slenderness, moment capacity and rotation ductility for EHS under constant bending moment. This configuration creates a constant moment zone along the central span with negligible shear. Various researchers have adopted this arrangement in their investigations: Schilling [10], Jirsa et al. [11], Korol and Hudoba [12], Sherman and Glass [13] and Jiao and Zhao [14] utilised this arrangement for testing on circular hollow sections (CHS), whilst Korol and Hudoba [12], Hasan and Hancock [15], Zhao and Hancock [16] and Wilkinson and Hancock [17] adopted this setup for testing on square and rectangular hollow sections (SHS and RHS). They utilised the test results and the derived moment-curvature relationships for the establishment of design rules.

Regarding the measurement of curvature, some researchers have used strain gauge measurements and calculated the curvature by dividing the algebraic differences of the extreme fibre surface strains by the section depth $[11,12,13,15,17]$. This clearly has shortcomings once local 
buckling has occurred. Others have employed displacement measurements at the loading points and mid-span to calculate the average curvature $[11,15,17]$, whilst Jiao and Zhao [14] used inclinometers to measure the angle of rotation at fixed positions within the constant moment span and hence derived the curvature. In this paper, measurements from linear variable displacement transducers (LVDTs) were used to provide the load-deflection histories as well as to derive the moment-curvature relationships.

A total of 10 four-point bending tests - 7 about the minor (z-z) axis and 3 about the major (y-y) axis - were conducted. A range of sections was tested to cover a spectrum of cross-section slendernesses. Mean measured geometric information for the specimens labelled with B1 and B2 (representing bending about the minor axis and major axis respectively) have been summarised in Table 2. Geometric imperfections were measured and the maximum local imperfections $\mathrm{w}_{0}$ have been reported in Table 2. A schematic illustration of the test setup and a view of the experimental arrangement are shown in Fig. 2. The lengths $\mathrm{L}_{1}, \mathrm{~L}_{2}$ and $\mathrm{L}_{3}$ are defined in Fig. 2 and are each equal to $1.5 \mathrm{~m}$ (i.e. length ratios $\mathrm{L}_{1} / \mathrm{L}_{2}$ or $\mathrm{L}_{3} / \mathrm{L}_{2}=1$ ). For bending about the minor axis, the minimum span-to-depth ratio was 18 , whilst for major axis bending, the minimum spanto-depth ratio was 9 . The tested beams were loaded symmetrically at the third points using two Instron Actuators. Three LVDTs were located at the loading points and the mid-span to measure the vertical deflections, whilst two additional LVDTs were positioned at each end of the beam to measure longitudinal displacements. Two linear electrical resistance strain gauges were affixed to the extreme tensile and compressive fibres of the section at a distance of $150 \mathrm{~mm}$ from the mid-span. Simple support conditions were provided by the roller system (Fig. 2) which was composed of a set of steel rods located between two metal plates allowing free longitudinally movement whilst the semi-spherical attachment to the end plate of the specimen allowed free rotation about the axis of bending. Load, strain, displacement and input voltage were all recorded using the data acquisition equipment DATASCAN and logged using the DSLOG computer 
package. The measurements of LVDT-1 and LVDT-2 at the loading points were used to calculate the average displacement $D_{L}$, at the loading points, while the mid-span LVDT-3

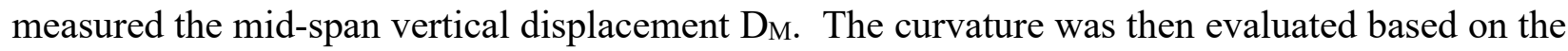
assumption that the deformed shape of the central span (of length $\mathrm{L}_{2}$ ) represents a segment of a circular arc (of radius $r$ ) which gives the curvature $\kappa$ defined by Eq. (7).

$$
\kappa=\frac{1}{r}=\frac{8\left(D_{M}-D_{L}\right)}{4\left(D_{M}-D_{L}\right)^{2}+L_{2}^{2}}
$$

The key results from the bending tests have been summarised in Table 3. Full moment-curvature relationships from the in-plane four-point bending tests were derived and are depicted in Figs 3 to 6. The four-point minor axis bending test results are shown from Figs 3 and 4 while Figs 5 and 6 represent the four-point major axis bending test results.

\subsubsection{Three-point bending tests}

The objective of the three-point bending tests was to establish a relationship between crosssection slenderness, moment capacity and rotation ductility for EHS subject to a moment gradient. This arrangement creates a moment gradient and uniform shear zone. A total of 8 three-point bending tests -4 about the minor (z-z) axis and 4 about the major (y-y) axis - were conducted. Again, a range of sections was tested to cover a spectrum of cross-section slendernesses. Mean measured geometric information, together with the imperfection data for the three-point bending specimens labelled with B3 and B4 (for bending about the minor axis and major axis respectively) have been summarised in Table 2. A schematic illustration of the test arrangement is shown in Fig. 7. Similarly to the four-point bending tests, symmetric span lengths $\mathrm{L}_{1}$ and $\mathrm{L}_{3}$ were chosen, each equal to $1.5 \mathrm{~m}$. For bending about the minor axis, the span-to-depth ratio was 15 , whilst for major axis bending, the span-to-depth ratio was 7.5. The tested beams were loaded at mid-span 
using an Amsler hydraulic actuator. The vertical displacement was measured with a LVDT, whilst two additional LVDTs were positioned at each end of the beam to measure longitudinal displacement and hence determine end rotation. Four linear electrical resistance strain gauges were affixed to the extreme tensile and compressive fibres of the section at a distance of $150 \mathrm{~mm}$ either side of the mid-span of the beam. Load, strain, displacement and input voltage were all recorded using the data acquisition equipment DATASCAN and logged using the DSLOG computer package. End rotation was calculated from the longitudinal displacement measurements through Eq. (8).

$$
\theta=\tan ^{-1} \frac{\left(\delta_{1}-\delta_{2}\right)}{H}
$$

where $\delta_{1}, \delta_{2}$ and $\mathrm{H}$ are defined in Fig. 7.

The key results from the bending tests have been summarised in Table 3. Full moment-rotation relationships for the in-plane three-point bending tests were derived and are depicted in Figs 8 to 11. The minor axis bending results are shown on Figs 8 and 9 whilst Figs 10 and 11 show the moment-rotation relationships for three-point major axis bending.

\subsubsection{Results}

The behaviour of beams under uniform bending differs from that under a moment gradient [18]: Under uniform bending, the bending moment remains constant (along a moment plateau) until the average outer fibre strain reaches the strain hardening strain $\varepsilon_{\text {sh }}$ along the entire uniform moment length. Only then may the bending moment rise above $\mathrm{M}_{\mathrm{pl}}$ [19]. This stable plateau has been observed in the four-point bending test results presented herein (Figs 3, 5 and 6). Conversely, for a beam under a moment gradient, the plastic hinge is localized to the point of maximum moment 
and strain hardening is experienced more readily allowing the bending moment to rise above $\mathrm{M}_{\mathrm{pl}}$. This moment will continue to increase until the yielded length of the compression flange corresponds to the local buckling wavelength [20]. This has also been observed in the three-point bending test results presented in this paper (Figs 9 to 11). These characteristics are best illustrated by considering the moment-curvature/rotation curves for specimens $400 \times 200 \times 12.5-$ B2 (Fig. 5) and $400 \times 200 \times 12.5-$ B4 (Fig. 10) bending about the major axis. For specimen $400 \times 200 \times 12.5-\mathrm{B} 2$, a stable plastic plateau can be observed prior to the onset of strain hardening after which the bending moment rises above $\mathrm{M}_{\mathrm{pl}}$, while for specimen $400 \times 200 \times 12.5-$ $\mathrm{B} 4$, the maximum moment region is concentrated at mid-span and strain hardening is ongoing as the bending moment rises beyond $\mathrm{M}_{\mathrm{pl}}$. It is also worth noting that for the same cross-section, the three-point bending specimen reached a higher maximum moment than its four-point bending counterpart. This is believed to be due to the stabilising effect from the stiffer material surrounding the plastic hinge, which is at a lower stress level in the three-point bending arrangement and helps to delay local buckling, whereas in four-point bending, the whole central region experiences constant moment and the point of local buckling receives less restraint.

\section{Numerical simulations}

A numerical modelling investigation, employing the finite element (FE) package ABAQUS [21], was carried out in parallel with the experimental programme. The primary aims of the investigation were to (1) replicate the experimental results, (2) validate the numerical models and (3) perform parametric studies. The elements chosen for the FE models were 4-noded, reduced integration shell elements with six degrees of freedom per node, designated as S4R in the ABAQUS element library, and suitable for thin or thick shell applications [21]. A uniform mesh density was carefully chosen by carrying out a mesh convergence study based on elastic 
eigenvalue predictions with the aim of achieving accurate results whilst minimising

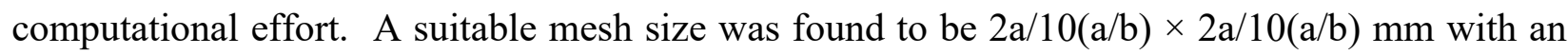
upper bound of $20 \times 20 \mathrm{~mm}$.

The in-plane bending tests were modelled using the measured dimensions of the test specimens and measured material stress-strain data. Both local and global geometric imperfections were included in the models. The form of the local geometric imperfections was taken to be the lowest local elastic eigenmode pattern. The local imperfection amplitude $\omega_{0}$ was considered as three fixed fractions of the material thickness $t(t / 10, t / 100$ and $t / 500)$, in addition to the measured imperfection values. The global imperfection pattern was assumed to be a half-sine wave given by $\omega_{\mathrm{g}} \sin (\pi \mathrm{x} / \mathrm{L})$, where $\mathrm{x}$ is the distance along the specimen, $\mathrm{L}$ is the specimen length and $\omega_{\mathrm{g}}$ is the global imperfection amplitude which was consistently taken as L/500 [6].

No residual stress data were measured, but two observations indicated that the level of residual stresses in the hot-rolled EHS was low: (1) negligible deformations occurred when the material tensile coupons were machined from the cross-sections and (2) a distinct yield point was seen in both the tensile coupon results and the stub column results [4], which high residual stresses would erode. Therefore, residual stresses were not incorporated into the numerical models in this study. The true material stress-strain relationships were generated from the engineering stress-strain curves obtained from the tensile coupon tests and material non-linearity was incorporated into the numerical models by means of a piecewise linear stress-strain model to replicate, in particular, the strain-hardening region.

Boundary conditions were applied to model simple support conditions at the ends of the beams and the vertical displacement at mid-span was monitored throughout the analysis. The modified Riks method [21] was employed to solve the geometrically and materially non-linear beam 
models, which enabled the post-ultimate behaviour to be traced. The numerical failure mode of $400 \times 200 \times 10-$ B3 is shown in Fig 12 and compared with the corresponding deformed test specimen. Results of the numerical simulations are tabulated in Table 4, in which, the ratios between the FE ultimate moment and the experimental moment are shown and compared for different imperfection levels.

Replication of test results was found to be satisfactory with the numerical models able to successfully capture the initial stiffness, ultimate load, general load-displacement response and failure patterns observed in the tests. Comparison between test and FE results are shown for specimen $400 \times 200 \times 12.5-$ B1 and $400 \times 200 \times 10.0-$ B3 in Figs 13 and 14, respectively. The ultimate moment capacity of the beam $400 \times 200 \times 8.0-$ B1 was consistently over-predicted by the numerical models, regardless of the imperfection amplitude. Possible explanations for this overprediction include variation of the material thickness around the cross-section and along the length of the beam and variation in material yield strength.

Sensitivity to imperfections was generally found to be relatively low, with the stockier sections showing the greatest variation in response. For example, in the case of the $400 \times 200 \times 16$ models, the ultimate load reduces by $12 \%$ with an increase of imperfection amplitude from $t / 100$ to $t / 10$. This sensitivity is due to the level of strain-hardening achieved by the constituent elements before local buckling occurs. The less stocky sections lie on or marginally below the yield plateau and are therefore less sensitive (in terms of ultimate load) to variation in the point of local buckling. Increased sensitivity would be anticipated for slender elliptical hollow sections where the yield load and elastic local buckling load were of similar value. However, as discussed in Chan and Gardner [4], the practical range of available elliptical hollow sections would be expected to be dominated by material yielding, and far higher cross-section slenderness is necessary before elastic buckling becomes dominant. 
Having verified the general ability of the FE models to replicate test behaviour for EHS with an aspect ratio of two, a series of parametric studies was conducted. The primary aim of the parametric studies was to investigate the influence of cross-section slenderness and aspect ratio on the ultimate load carrying capacity and deformation capacity of EHS. A typical piecewise linear material stress-strain model was adopted from the conducted tensile coupon tests as shown in Fig. 15. Initial local geometric imperfections in the non-linear parametric analyses adopted the form of the lowest elastic local eigenmode whilst the global geometric imperfections pattern was assumed to be a half-sine wave. The section sizes considered in the parametric studies were $400 \times 400,400 \times 200$ and $400 \times 133.3$ with varying thickness to cover a spectrum of cross-section slendernesses. The parametric studies include both symmetric three-point and four-point bending arrangements with span length ratios $\left(\mathrm{L}_{1} / \mathrm{L}_{2}\right.$ and $\left.\mathrm{L}_{3} / \mathrm{L}_{2}\right)$ equal to unity. The results have been utilized for the validation of proposed slenderness parameters and cross-section classification limits for elliptical hollow sections and are discussed in detail in the following section.

\section{Cross-section classification}

The majority of structural steel design codes including Eurocode 3, place cross-sections into discrete behavioural classes based upon their susceptibility to local buckling. Class 1 crosssections are capable of reaching and maintaining their full plastic moment in bending (and may therefore be used in plastic design). Sufficient deformation capacity or rotation capacity has to be demonstrated in this behavioural class. Class 2 cross-sections are also capable of reaching their full plastic moment in bending but have somewhat lower deformation capacity. In Class 3 crosssections, local buckling prevents attainment of the full plastic moment and the bending moment resistance is limited to the yield (elastic) moment. For Class 4 cross-sections, local buckling 
occurs in the elastic range and bending resistance is determined on the basis of an effective crosssection defined by the width-to-thickness (or diameter-to-thickness) ratios of the constituent elements. The moment-rotation characteristics of the four behavioural classes are summarized in Fig. 16.

\subsection{Slenderness parameters}

Central to the cross-section classification approach are the measures of slenderness - the crosssection slenderness parameters. These parameters have been derived based upon the physical response of EHS under different loading conditions with regard to the manifestation of local buckling in the elastic range. As discussed in Chan and Gardner [4], when an EHS is subjected to axial compression, local buckling initiates at the point of maximum radius of curvature, where $r_{\max }=a^{2} / b$. It has therefore been proposed that the cross-section slenderness parameter for axial compression is defined as follows.

$$
\frac{\mathrm{D}_{\mathrm{e}}}{\mathrm{t} \varepsilon^{2}}=2 \frac{\left(\mathrm{a}^{2} / \mathrm{b}\right)}{\mathrm{t} \varepsilon^{2}}
$$

where $\mathrm{D}_{\mathrm{e}}$ is the equivalent diameter and $\varepsilon^{2}=235 / \sigma_{\mathrm{y}}$ is to allow for a range of yield strengths.

Similarly, for bending about the minor (z-z) axis, the maximum compressive stress coincides with the point of maximum radius of curvature. Therefore, it is proposed that the same crosssection slenderness parameter given by Eq. (9) can be adopted.

For bending about the major (y-y) axis, as discussed earlier, buckling would initiate in general neither at the point of maximum radius of curvature (located at the neutral axis of the crosssection with negligible bending stress) nor at the extreme of the major axis where the maximum 
compressive stress occurs but where the cross-section is of greatest stiffness. Gerard and Becker [22] observed that in this bending situation, determination of the elastic buckling stress involves the location of a point of critical radius of curvature. This critical radius of curvature $r_{c r}$ was calculated by optimizing the function composed of the varying curvature expression and the elastic bending stress distribution and was found to be equal to $0.65 \mathrm{a}^{2} / \mathrm{b}$ (Fig. 17). For an aspect ratio $\mathrm{a} / \mathrm{b}$ of less than 1.155 , where the section is approaching circular, Gerard and Becker [22] observed that buckling would always occur at the extreme of the major axis and that $r_{c r}$ would therefore be equal to a. However, at the extreme of the major axis, the radius of curvature is, in fact, equal to $b^{2} / a$. For a/b less than $1.155, \mathrm{r}_{c r}$ has therefore been taken as $b^{2} / a$ herein. As described above, for an elliptical hollow section in major axis bending with an aspect ratio $\mathrm{a} / \mathrm{b}$ of two, elastic critical buckling would initiate, theoretically, at a distance $0.42 \mathrm{a}\left(\mathrm{r}=0.65 \mathrm{a}^{2} / \mathrm{b}\right)$ from the extreme fibre in compression. However, from the experimental results, use of the radius at a distance of $0.22 \mathrm{a}\left(\mathrm{r}=0.4 \mathrm{a}^{2} / \mathrm{b}\right)$ from the extreme compressive fibre more closely reflects the observed physical behaviour (see Fig. 18).

Thus, for a general slenderness parameter in major axis bending for the cross-section classification of EHS, it is proposed to utilize the findings of Gerard and Becker [22] based on an elastic stress distribution, with modification based on observed physical behaviour. The proposed slenderness parameters are therefore given by Eq. (10) and Eq. (11).

$$
\begin{array}{ll}
\frac{D_{e}}{t \varepsilon^{2}}=0.8 \frac{\left(a^{2} / b\right)}{t \varepsilon^{2}} & \text { for } a / b>1.155 \\
\frac{D_{e}}{t \varepsilon^{2}}=2 \frac{\left(b^{2} / a\right)}{t \varepsilon^{2}} & \text { for } a / b \leq 1.155
\end{array}
$$

Note that for the special case of an EHS with an aspect ratio of unity, the cross-section 
slenderness defined by Eq. (11) reverts to that for CHS in Eurocode 3.

\subsection{Class 3 and Class 4 cross-sections}

The distinction between Class 3 and 4 cross-sections relates to their ability to reach the elastic moment resistance $M_{e l}$. The relationship between test $M_{u} / M_{e l}$, where $M_{u}$ is the maximum moment reached in the test, and the proposed cross-section slenderness parameters given by Eqs (9) to (11) is plotted in Figs 19 and 20 for bending about the minor axis and major axis respectively. A value of $\mathrm{Mu} / \mathrm{Mel}$ greater than unity represents meeting of the Class 3 requirement, whilst a value less than unity indicates a Class 4 cross-section where local buckling prevents the yield moment being reached. A lower bound to the experimental results in both figures suggests that the Eurocode slenderness limit of 90 [23] representing the boundary between Class 3 and 4 cross-sections may be safely adopted. For comparison, existing bending test data from hotformed CHS [24, 25] and hot-formed seamless tubes [10, 11, 26, 27] have been plotted in Figs 19 and 20. In addition to the experimental results, results from the described parametric studies on elliptical hollow sections with aspect ratios a/b of 1, 2 and 3 have also been plotted in Figs 19 and 20 complementing the experimental results in illustrating the appropriateness of adopting the Eurocode limit. Further analysis of the results indicates that the Class 3 slenderness limit for both CHS and EHS (bending about either axis) may be relaxed to $140 \varepsilon^{2}$.

An interim effective section modulus formula ( $\mathrm{W}_{\text {eff }}$ ) for Class 4 (slender) elliptical hollow sections has been developed with reference to the formulation for circular hollow sections in BS 5950-1 [28]. This proposed formula for EHS is given by Eq. (12).

$$
\mathrm{W}_{\mathrm{eff}}=\mathrm{W}_{\mathrm{el}}\left[\frac{140}{\mathrm{D}_{\mathrm{e}} / \mathrm{t}} \frac{235}{\sigma_{\mathrm{y}}}\right]^{0.25}
$$


For the current range of elliptical hollow sections, based upon the experimental and numerical results, Eq. (12) has been found to be conservative and can be safely adopted for Class 4 (slender) elliptical hollow sections. Further investigation into effective section formulations is currently underway.

\subsection{Class 1 and Class 2 cross-sections}

Both Class 1 and Class 2 cross-sections are capable of reaching their plastic bending moment resistance. Distinction between these two classes is made on the basis of their rotation capacity R.

In plastic design, members must be capable of forming plastic hinges which allow rotation whilst sustaining the plastic moment resistance until a collapse mechanism is formed. The total rotation of the first plastic hinge to form in a collapse mechanism defines the rotation requirement or rotation demand of the structure. This requirement varies for different structural configurations, loading arrangements, geometry, material strengths and level of seismicity and has been widely studied in the literature, particularly for continuous beams and frames [29, 30, 31].

The rotation capacity, on the other hand, represents the ability of a cross-section to satisfy the rotation requirement. This capacity $\mathrm{R}$ may be determined by two commonly adopted methods. One is evaluated from the moment-curvature relationship and the other is based on the momentrotation behaviour. The former method has been widely utilised in the literature for the study of cold-formed steel sections $[12,15,16,17]$ and recently on high strength steel sections [14] in a four-point bending arrangement. The rotation capacity $\mathrm{R}$ of a plastic hinge based on the momentcurvature relationship is defined by Eq. (13).

$$
\mathrm{R}=\frac{\kappa_{\mathrm{rot}}}{\kappa_{\mathrm{pl}}}-1
$$


where $\kappa_{\mathrm{pl}}$ is evaluated as $\mathrm{Mpl} / \mathrm{EI}$ and $\kappa_{\mathrm{rot}}$ is the limiting curvature at which the moment resistance drops back below $\mathrm{M}_{\mathrm{pl}}$ (Fig. 21).

Similarly, the definition of rotation capacity based on the moment-rotation relationship (Fig. 21) has been commonly used in the literature $[9,24,25,32]$. Rotation capacity based on the moment-rotation relationship is defined by Eq. (14).

$$
\mathrm{R}=\frac{\theta_{\text {rot }}}{\theta_{\mathrm{pl}}}-1
$$

where $\theta_{\mathrm{pl}}$ is the elastic component of rotation upon reaching $\mathrm{M}_{\mathrm{pl}}$ and $\theta_{\text {rot }}$ is the limiting rotation at which the moment resistance falls back below $\mathrm{M}_{\mathrm{pl}}$.

In the development of modern steel design codes for plastic design, national or regional reference values for rotation capacity have been established on the basis of available analytical, experimental and numerical studies. Design rules have then been developed with reference to this rotation capacity. Korol and Hudoba [12] recommended a rotation capacity of 4 for plastic design using cold-formed structural hollow sections. Design rules for limiting width-to-thickness ratios were then developed. This rotation capacity was further adopted by Hasan and Hancock [15], Zhao and Hancock [16] and Wilkinson and Hancock [17] for their contribution to the Australian standard [33].

The North American standard has assumed a rotation capacity of 3 to be sufficient for most civil engineering structures as indicated in Yura et al. [34] and AISC [35, 36]. This rotation capacity of 3 is based on limiting the flange strain to four times the yield strain. The North American 
standard has then derived their limiting width-to-thickness ratios for compact sections on the basis of this value.

Similarly, in the background document to the European standard, Bild et al. [37] and Sedlacek and Feldmann [32] investigated and summarised the rotation requirements for three-span continuous beams and single bay frames under point loads. They concluded that a rotation capacity of 3 is sufficient and corresponding limiting width-to-thickness ratios for Class 1 sections were developed. Stranghöner et al. [9] also performed parametric studies into the rotation requirements on square, rectangular and circular hollow sections on a three-span continuous beam subjected to a point load in the central span. The investigated factors included beam geometry, loading, cross-section, material and serviceability requirements. Results demonstrated a rotation capacity of 3 is sufficient. Other researchers $[24,25]$ also utilised this value of 3 in their studies.

In this paper, a rotation capacity of 3 has been adopted for the development of the Class 1 classification limit, which is same as the rotation capacity adopted in the development of the current European [23] and North American [35, 36] steel design codes. The rotation capacity of the cross-sections has been studied under two fundamental static loading arrangements (1) constant moment and (2) a moment gradient.

The four-point bending configuration enables the study of the cross-section behaviour under uniform moment with negligible influence from shear. The definition of rotation capacity based on the moment-curvature relationship (Eq. (13)) was therefore adopted for evaluating the fourpoint bending test and numerical results. The three-point bending arrangement allows study of the cross-section behaviour under a moment gradient and in the presence of shear, and in this case the moment-rotation relationship (Eq. (14)) was used to evaluate rotation capacity from the 
test and numerical results.

As discussed in Section 2.2.3, the behaviour of beams under uniform bending (four-point bending) differs from that under a moment gradient (three-point bending). To account for the initial spread of plasticity along the uniform moment region (when the bending moment generally lies just below $\mathrm{M}_{\mathrm{pl}}$ ) and to reduce subjective interpretation of test results from uniform bending arrangements, researchers $[19,25]$ have suggested that rotation capacity should be determined at a reduced plastic moment $0.95 \mathrm{Mpl}$. Thus, for uniform bending, rotation capacity $\mathrm{R}_{0.95}$ is defined by Eq. (15).

$$
\mathrm{R}_{0.95}=\frac{\kappa_{\mathrm{rot}, 0.95}}{\kappa_{\mathrm{pl}, 0.95}}-1
$$

The results from the four-point bending tests presented herein support this proposal and hence the above definition has been used throughout this paper to determine rotation capacity for beams in the four-point bending arrangement.

The ultimate moments attained in the tests have been normalised against the plastic moment resistance $\left(\mathrm{M}_{\mathrm{pl}}\right.$ for three-point bending and $0.95 \mathrm{M}_{\mathrm{pl}}$ for four-point bending assuring consistent interpretation of the results as for the rotation capacity) and plotted against cross-section slenderness, as given by Eqs (9) to (11) in Figs 22 and 23. A value of $M_{u} / 0.95 M_{p l}$ or $M_{u} / M_{p l}$ greater than unity represents meeting of the Class 2 requirement, while a value less than unity indicates a Class 3 or Class 4 cross-section where local buckling prevents attainment of the full plastic moment. The data generally indicate that the EN 1993-1-1 [23] Class 2 limit may be safely adopted. For comparison, existing bending test data from hot-formed circular hollow sections (CHS) [10, 11, 24, 25, 26, 27] have also been added to Figs 22 and 23. This is further 
supported by the parametric results on EHS with aspect ratios of 1,2 and 3. It is worth noting that the three stockiest experimental points in Fig. 22 relate to the tests described by Eckhardt [38] where the ultimate moment resistance was not reached.

Both Class 1 and Class 2 cross-sections are capable of reaching their plastic bending moment resistance $\left(0.95 \mathrm{M}_{\mathrm{pl}}\right.$ for four-point bending and $\mathrm{M}_{\mathrm{pl}}$ for three-point bending). Distinction between these two classes is made on the basis of rotation capacity R. Figs 24 and 25 plot rotation capacity (as defined by Eqs (13) to (15)) against cross-section slenderness. As discussed earlier, a rotation capacity $\mathrm{R}$ of 3 is required for a Class 1 cross-section to permit moment redistribution in indeterminate structures. From a lower bound analysis of the test data, a Class 1 classification limit of 50 from EN 1993-1-1 [23] may be safely adopted. For comparison, existing bending test data from hot-formed CHS [24, 25] have also been added to Figs 24 and 25. This is further supported by the parametric results on EHS with aspect ratios of 1, 2 and 3 .

\section{Conclusions}

In this paper, the first comprehensive set of experimental data for the in-plane bending of elliptical hollow sections has been presented. The experimental programme comprised 12 tensile coupon tests and 18 in-plane bending tests. Two configurations - four-point bending and threepoint bending - were employed and described. Full moment-curvature and moment-rotation responses have been reported, including into the post-ultimate range. The experimental results were replicated by means of non-linear numerical modelling. Following careful validation of the models, parametric studies were performed to assess the structural response of EHS over a wider range of aspect ratios (between one (CHS) and three) and cross-section slendernessess. For design, cross-section classification parameters have been proposed and classification limits, in 
harmony with the EC3 limits for CHS, have been derived. An effective section modulus formulation for Class 4 (slender) sections has also been proposed. This research forms part of a wider study of the structural behaviour of elliptical hollow sections currently being conducted at Imperial College London.

\section{Acknowledgements}

The authors are grateful to the Dorothy Hodgkin Postgraduate Award Scheme for the project funding, and would like to thank Corus Tubes for the supply of test specimens and for funding

contributions, Eddie Hole and Andrew Orton (Corus Tubes) for their technical input and Ron Millward, Alan Roberts and Trevor Stickland for their assistance in the laboratory works. 


\section{Symbols}

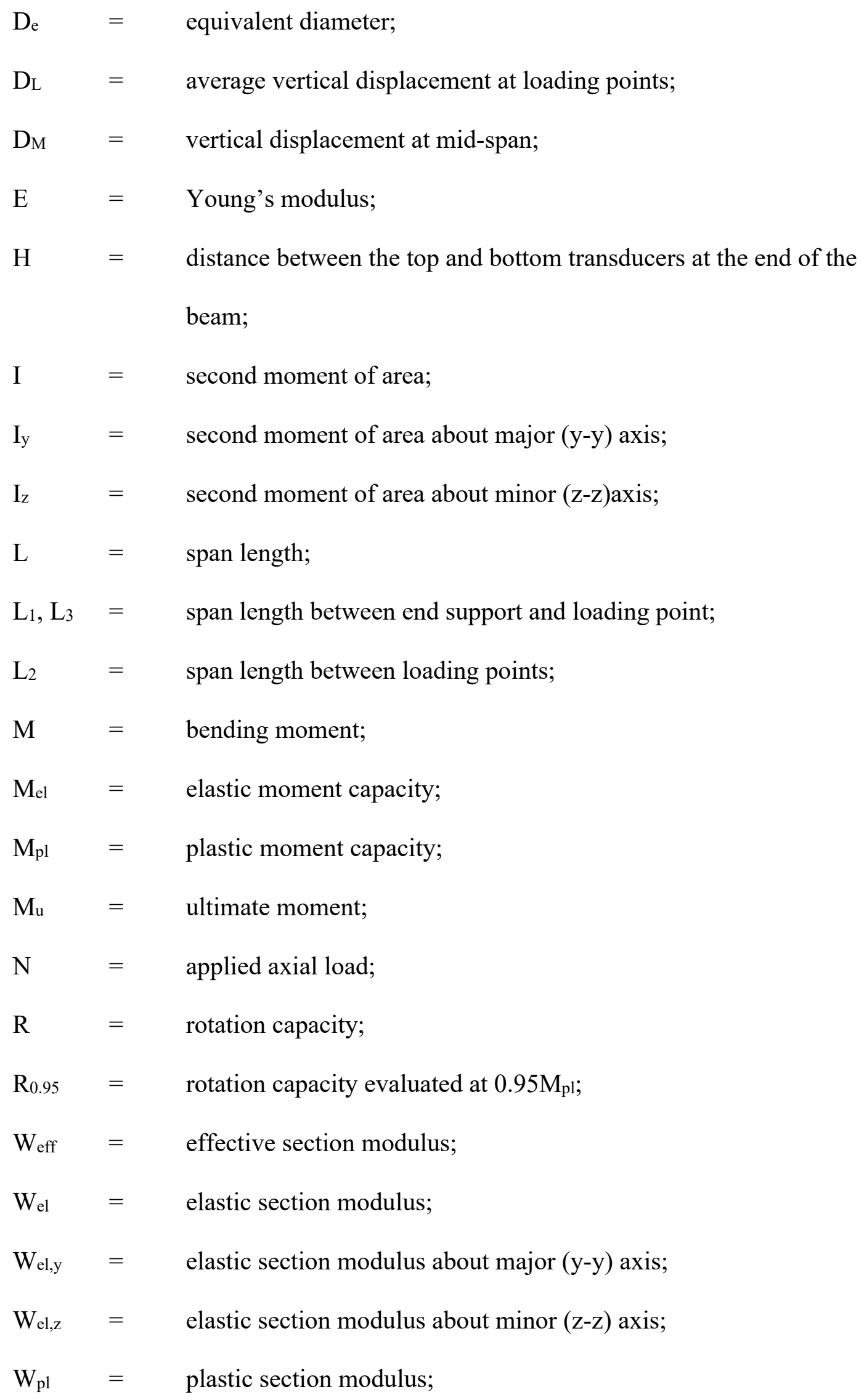




$$
\begin{aligned}
& \mathrm{W}_{\mathrm{pl}, \mathrm{y}}=\quad \text { plastic section modulus about major }(\mathrm{y}-\mathrm{y}) \text { axis; } \\
& \mathrm{W}_{\mathrm{pl}, \mathrm{z}}=\quad \text { plastic section modulus about minor }(\mathrm{z}-\mathrm{z}) \text { axis; }
\end{aligned}
$$

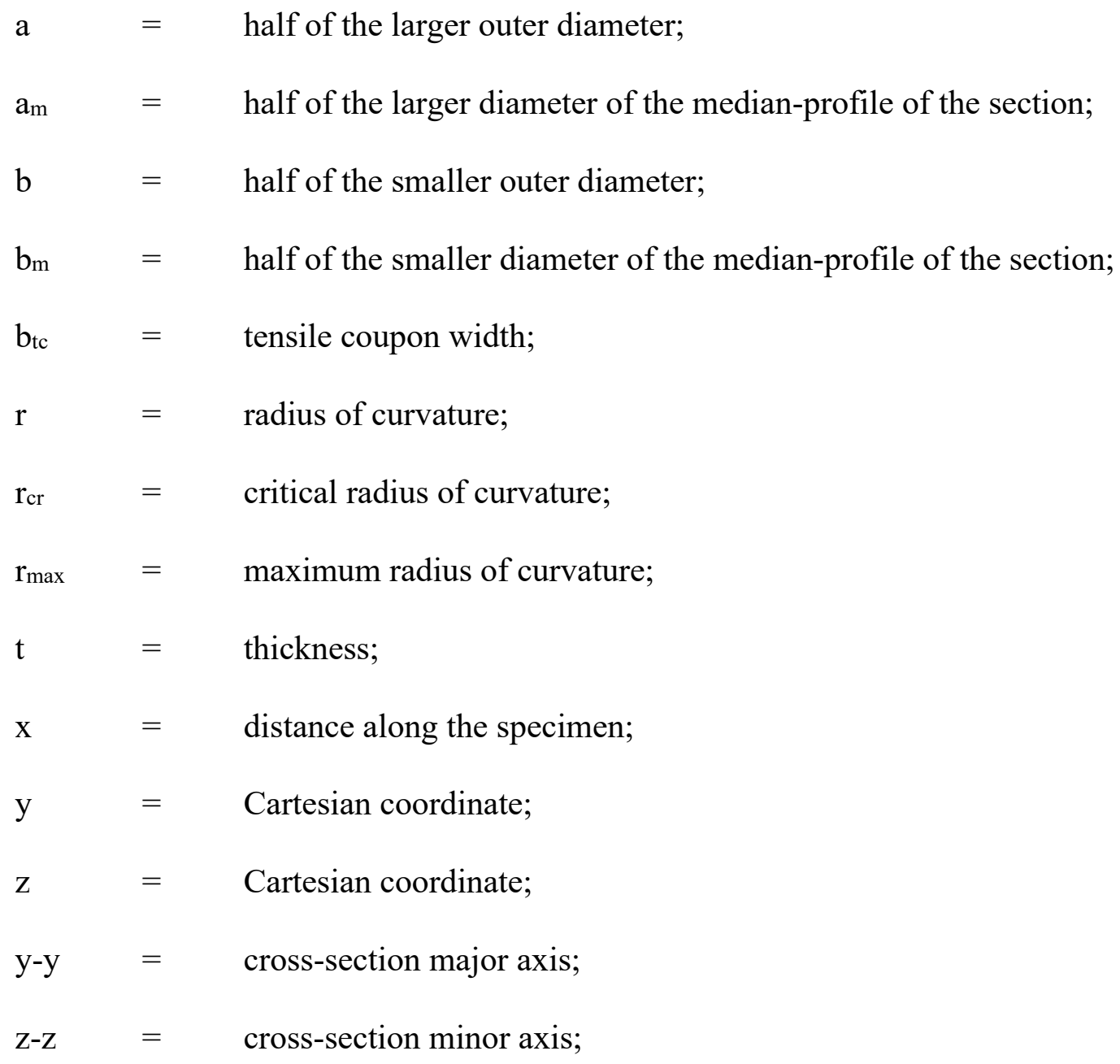

$\delta \quad=\quad$ vertical displacement at mid-span of beam;

$\delta_{1}=$ horizontal displacement at the end of the beam (top transducer);

$\delta_{2}=$ horizontal displacement at the end of the beam (bottom transducer);

$\varepsilon \quad=\quad$ coefficient dependant on the material yield stress;

$\varepsilon_{\text {sh }} \quad=\quad$ strain hardening strain;

$\phi \quad=\quad$ angle measured from the $\mathrm{z}-\mathrm{z}$ axis;

$\kappa=$ curvature; 


\begin{tabular}{|c|c|c|}
\hline$\kappa_{\mathrm{pl}}$ & $=$ & elastic component of curvature upon reaching $\mathrm{Mpl}_{\mathrm{pl}}$ \\
\hline$\kappa_{\mathrm{pl}, 0.95}$ & $=$ & elastic component of curvature upon reaching $0.95 \mathrm{M}_{\mathrm{pl}}$ \\
\hline$\kappa_{\text {rot }}$ & $=$ & curvature at which moment resistance drops back below $\mathrm{M}_{\mathrm{pl}}$ \\
\hline$\kappa_{\text {rot }, 0.95}$ & $=$ & curvature at which moment resistance drops back below $0.95 \mathrm{M}_{\mathrm{pl}}$; \\
\hline$\kappa_{u}$ & $=$ & curvature at ultimate moment; \\
\hline$\theta$ & $=$ & rotation; \\
\hline$\theta_{\mathrm{pl}}$ & $=$ & elastic component of rotation upon reaching $\mathrm{M}_{\mathrm{pl}}$ \\
\hline$\theta_{\text {rot }}$ & $=$ & rotation at which moment resistance drops back below $\mathrm{M}_{\mathrm{pl}}$ \\
\hline$\theta_{\mathrm{u}}$ & $=$ & rotation at ultimate moment; \\
\hline$\sigma_{u}$ & $=$ & ultimate tensile stress; \\
\hline$\sigma_{y}$ & $=$ & material yield stress; \\
\hline$\omega_{\mathrm{g}}$ & $=$ & global imperfection; \\
\hline$\omega_{0}$ & $=$ & local imperfection. \\
\hline
\end{tabular}




\section{References}

[1] McKechnie, S. (2006). Terminal 5, London Heathrow: The main terminal building envelope. The Arup Journal, 41(2), 36-43.

[2] Gardner, L. and Ministro, A. (2005). Structural steel oval hollow sections. The Structural Engineer, 83(21), 32-36.

[3] Chan, T. M. and Gardner, L. (2006). Experimental and numerical studies of elliptical hollow sections under axial compression and bending. Proceedings of the $11^{\text {th }}$ International Symposium on Tubular Structures, $31^{\text {st }}$ August to $2^{\text {nd }}$ September 2006, Québec City, Canada, 163-170.

[4] Chan, T. M. and Gardner, L. (in press). Compressive resistance of hot-rolled elliptical hollow sections. Engineering Structures, doi:10.1016/j.engstruct. 2007.04.019.

[5] Gardner, L. and Chan, T. M. (2007). Cross-section classification of elliptical hollow sections. Steel and Composite Structures, 7(3), 185-200.

[6] EN 10210-2 (2006). Hot finished structural hollow sections of non-alloy and fine grain steels - Part 2: Tolerances, dimensions and sectional properties. CEN.

[7] Corus (2006). Celsius ${ }^{\circledR} 355$ Ovals - Sizes and resistances Eurocode version. Corus Tubes - Structural \& Conveyance Business. 
[8] Gioncu, V. and Petcu, D. (1997). Available rotation capacity of wide-flange beams and beam-columns, Part 1. Theoretical Approaches. Journal of Constructional Steel Research, 43(1-3), 161-217.

[9] Stranghöner, N., Sedlacek, G. and Boeraeve, Ph. (1994). Rotation requirement and rotation capacity of rectangular, square and circular hollow section beams. Proceedings of the $6^{\text {th }}$ International Symposium on Tubular Structures, $14^{\text {th }}$ to $16^{\text {th }}$ December 1994, Melbourne, Australia, 143-150.

[10] Schilling, C. G. (1965). Buckling strength of circular tubes. Journal of the Structural Division. ASCE, 91(5), 325-348.

[11] Jirsa, J. O., Lee, F. H., Wilhoit, J. C. and Merwin, J. E. (1972). Ovaling of pipelines under pure bending. Proceedings of the $4^{\text {th }}$ Annual Offshore Technology Conference, $1^{\text {st }}$ to $3^{\text {rd }}$ May 1972, Houston, USA. .

[12] Korol, R. M. and Hudoba, J. (1972). Plastic behavior of hollow structural sections. Journal of the Structural Division, ASCE, 98(5), 1007-1023.

[13] Sherman, D. R. and Glass, A. M. (1974). Ultimate bending capacity of circular tubes. Proceedings of the $6^{\text {th }}$ Annual Offshore Technology Conference, May 1974, Houston, USA.

[14] Jiao, H. and Zhao, X. L. (2004). Section slenderness limits of very high strength 
circular steel tubes in bending. Thin-Walled Structures, 42(9), 1257-1271.

[15] Hasan, S. W. and Hancock, G. J. (1989). Plastic bending tests of cold-formed rectangular hollow sections. Steel Construction, Journal of Australian Institute of Steel Construction, 23(4), 2-19.

[16] Zhao, X. L. and Hancock, G. J. (1991). Tests to determine plate slenderness limits for cold-formed rectangular hollow sections of grade C450. Steel Construction, Journal of Australian Institute of Steel Construction, 25(4), 2-16.

[17] Wilkinson, T. and Hancock, G. J. (1998). Tests to examine compact web slenderness of cold-formed RHS. Journal of Structural Engineering, ASCE, 124(10), $1166-1174$.

[18] Galambos, T. V. (1968). Deformation and energy absorption capacity of steel structures in the inelastic range. Bulletin No.8, American Iron and Steel Institute.

[19] Lay, M. G. and Galambos, T. V. (1965). Inelastic steel beams under uniform moment. Journal of the Structural Division, ASCE, 91(6), 67-93.

[20] Lay, M. G. and Galambos, T. V. (1967). Inelastic beams under moment gradient. Journal of the Structural Division, ASCE, 93(1), 381-399.

[21] ABAQUS (2006). ABAQUS, Version 6.6. Hibbitt, Karlsson \& Sorensen, Inc. Pawtucket, USA. 
[22] Gerard, G and Becker, H. (1957). Handbook of structural stability: Part III Buckling of curved plates and shells. Technical Note 3783, NACA.

[23] EN 1993-1-1 (2005). Eurocode 3: Design of steel structures - Part 1-1: General rules and rules for buildings. CEN.

[24] Rondal, J., Boeraeve, Ph., Sedlacek, G., Stranghöner, N. and Langenberg, P. (1995). Rotation capacity of hollow beam sections. CIDECT.

[25] Sedlacek, G., Dahl, W., Stranghöner, N., Kalinowski, B., Rondal, J. and Boreaeve, Ph. (1998). Investigation of the rotation behaviour of hollow section beams. EUR 17994 EN, European Commission.

[26] Sherman, D. R. (1976). Tests of circular steel tubes in bending. Journal of the Structural Division, ASCE, 102(11), 2181-2195.

[27] Sherman, D. R. (1986). Inelastic flexural buckling of cylinders. Proceedings of the Steel Structures: Recent Research Advances and Their Applications to Design, $30^{\text {th }}$ September to $2^{\text {nd }}$ October 1986, Budva, Yugoslavia, 339-357.

[28] BS 5950-1 (2000). Structural use of steelwork in building - Part 1: Code of practice for design - Rolled and welded sections. BSI.

[29] Driscoll, G. C. (1958). Rotation capacity requirements for beams and portal frames. PhD Thesis, Lehigh University. 
[30] Kerfoot, R. P. (1965). Rotation capacity of beams. Report 297.14, Fritz Engineering Laboratory, Lehigh University.

[31] ASCE (1971). Plastic design in steel: A guide and commentary. Manual and Report on Engineering Practice, No. 41, Second edition, Welding Research Council and ASCE.

[32] Sedlacek, G. and Feldmann, M. (1995). Background document 5.09 for chapter 5 of Eurocode 3 Part 1.1 - The b/t ratios controlling the applicability of analysis models in Eurocode 3 Part 1.1. Aachen.

[33] AS 4100 (1998). Steel structures. Australian Standard.

[34] Yura, J. A., Galambos, T. V. and Ravindra, M. K. (1978). The bending resistance of steel beams. Journal of Structural Division, ASCE, 104(9), 1355-1370.

[35] AISC (2005). Specification for structural steel buildings. American Institute of Steel Construction.

[36] AISC (2005). Commentary on the specification for structural steel buildings. American Institute of Steel Construction.

[37] Bild, St., Roik, K., Sedlacek, G, Stutzki, Ch. and Spangemacher, R. (1989). Background document for chapter 5 of Eurocode 3 - The b/t-ratios controlling the applicability of analysis models in Eurocode 3. Draft, Aachen. 
[38] Eckhardt, C. (2004). Classification of oval hollow sections. University of Southampton. 


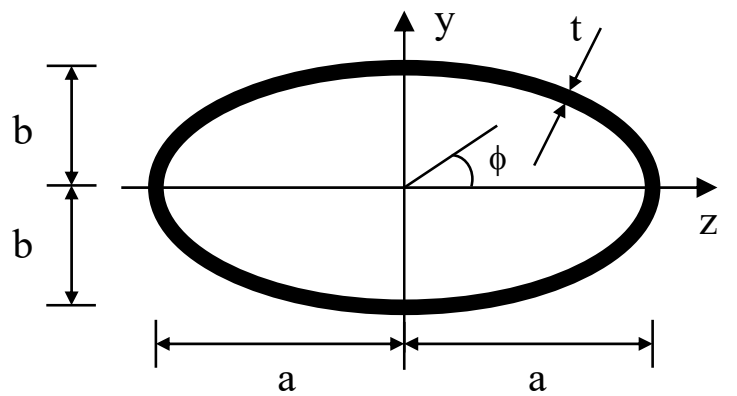

Fig. 1. Geometry of an elliptical hollow section. 


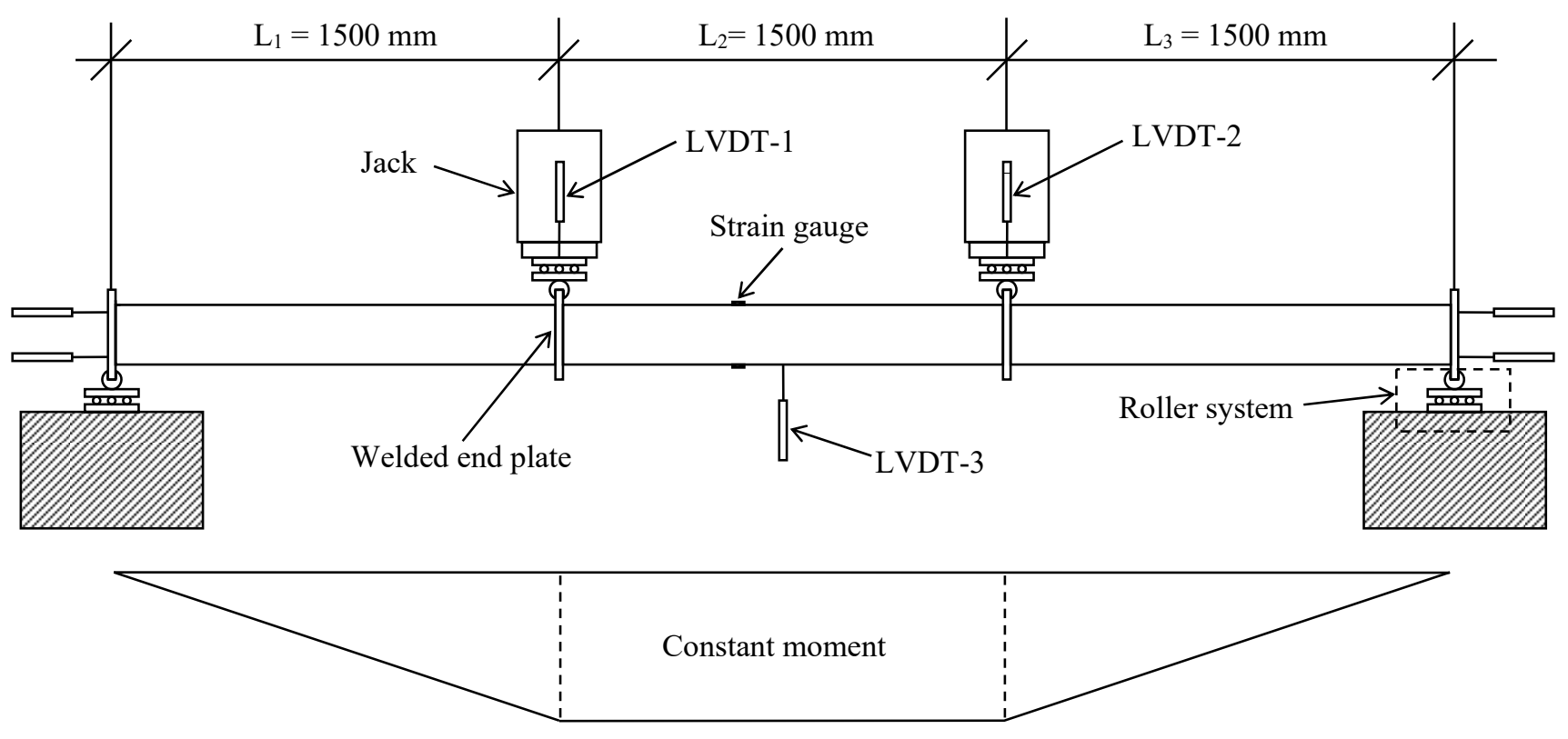

(a) Schematic setup

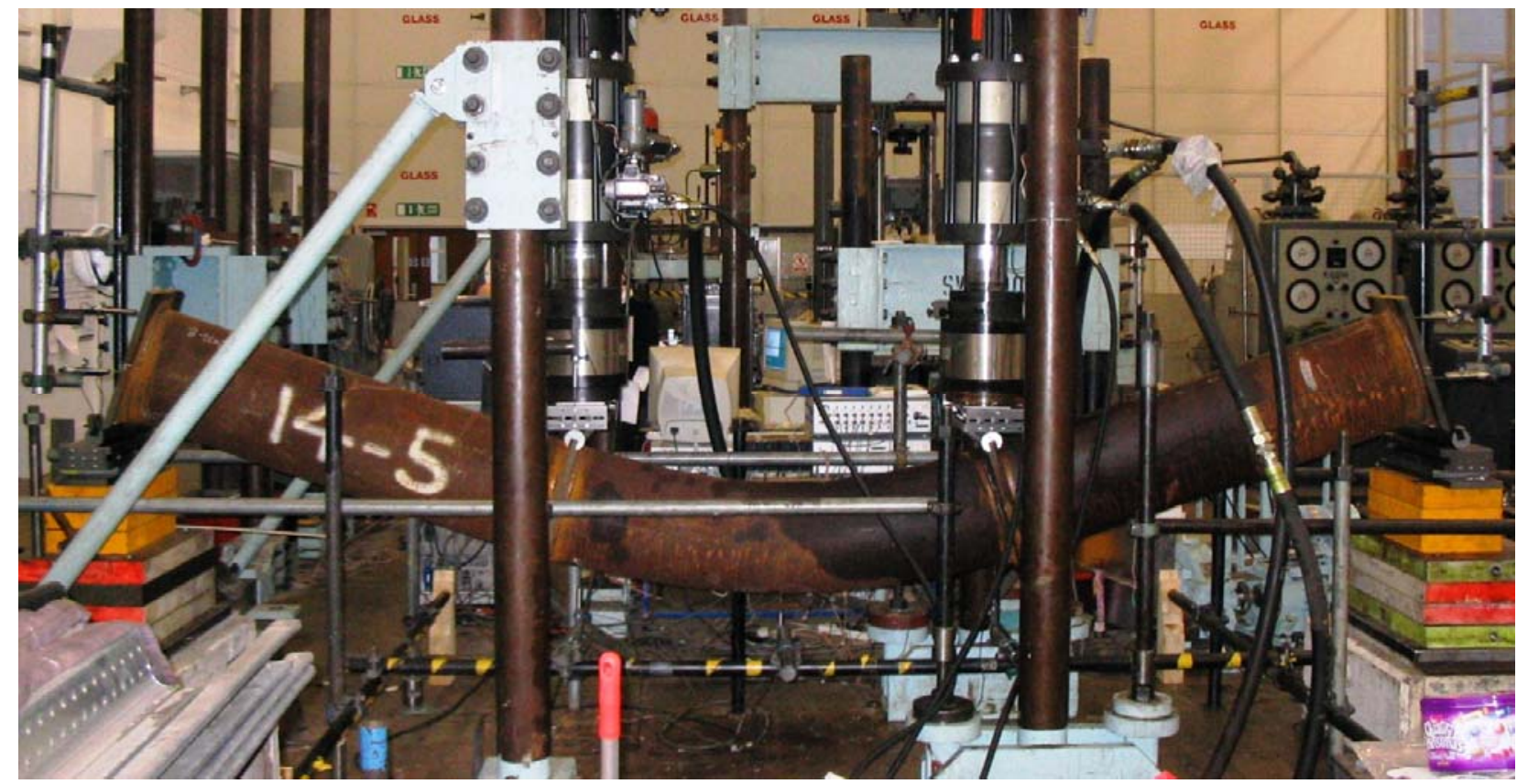

(b) Experimental Setup

Fig. 2. Four-point bending tests. 


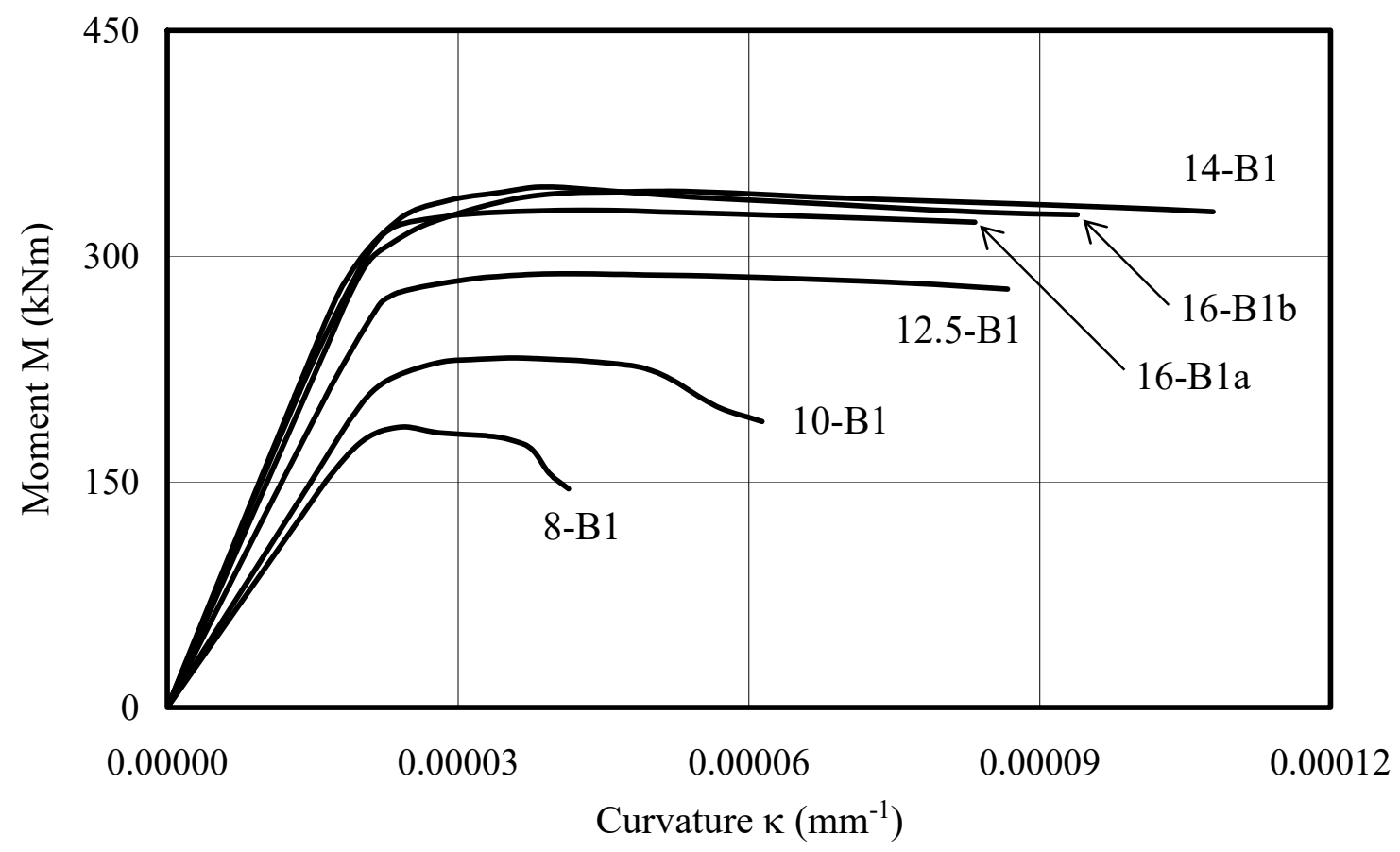

Fig. 3. Moment-curvature responses of $400 \times 200$ beams in four-point minor axis bending.

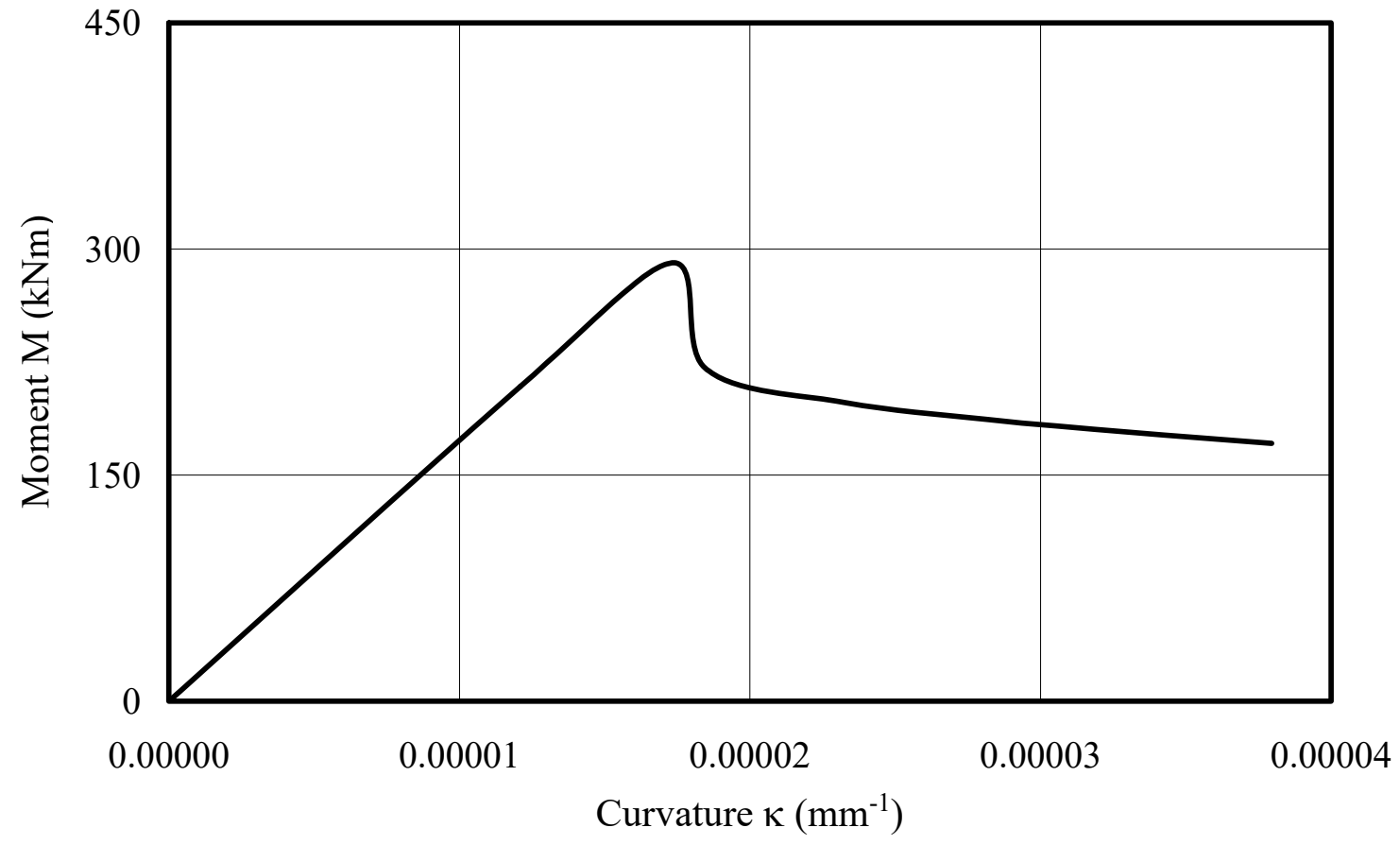

Fig. 4. Moment-curvature response of $500 \times 250 \times 8.0-\mathrm{B} 1$ beam in four-point minor axis bending. 


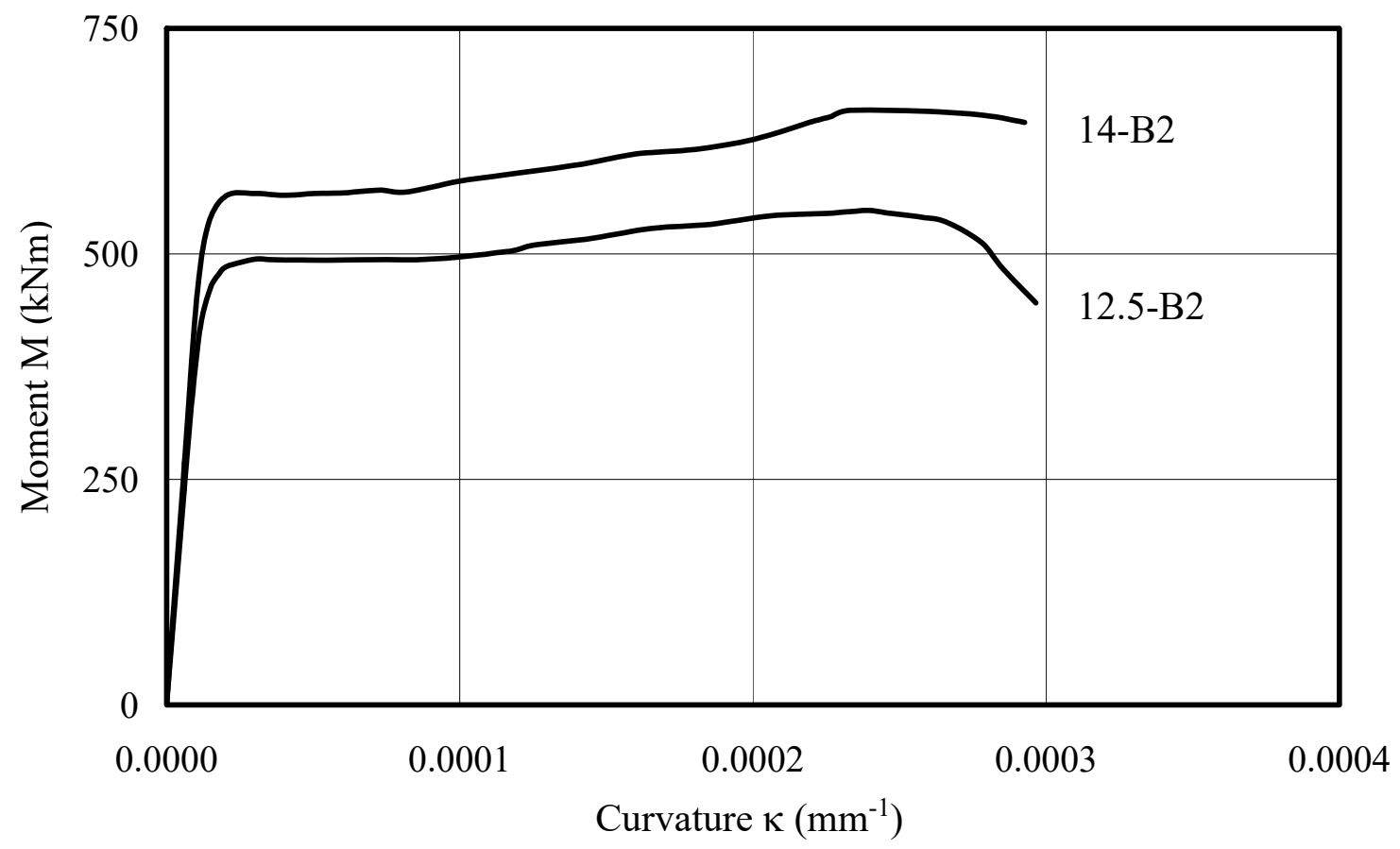

Fig. 5. Moment-curvature responses of $400 \times 200$ beams in four-point major axis bending.

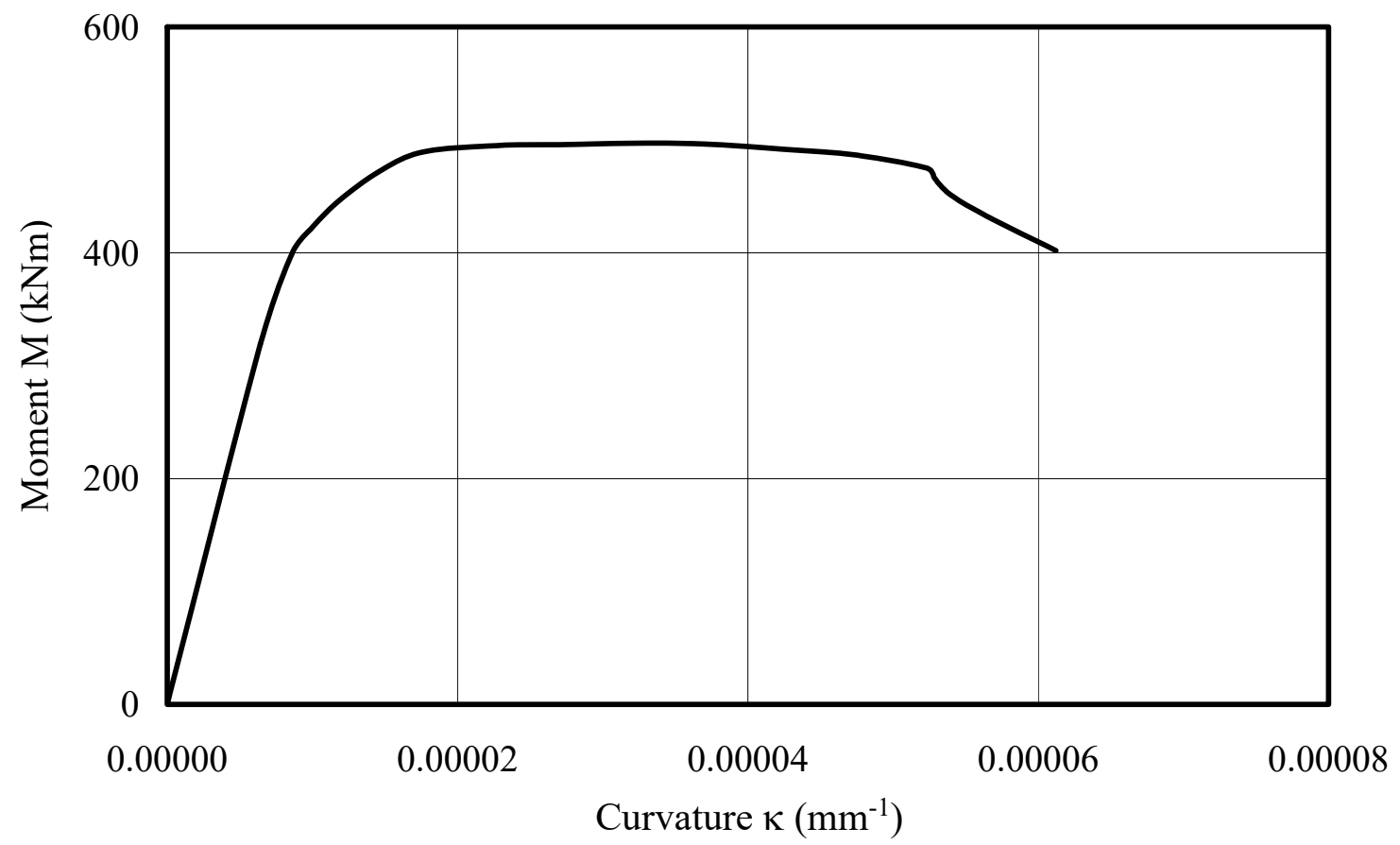

Fig. 6. Moment-curvature response of $500 \times 250 \times 8.0-\mathrm{B} 2$ beam in four-point major axis bending. 

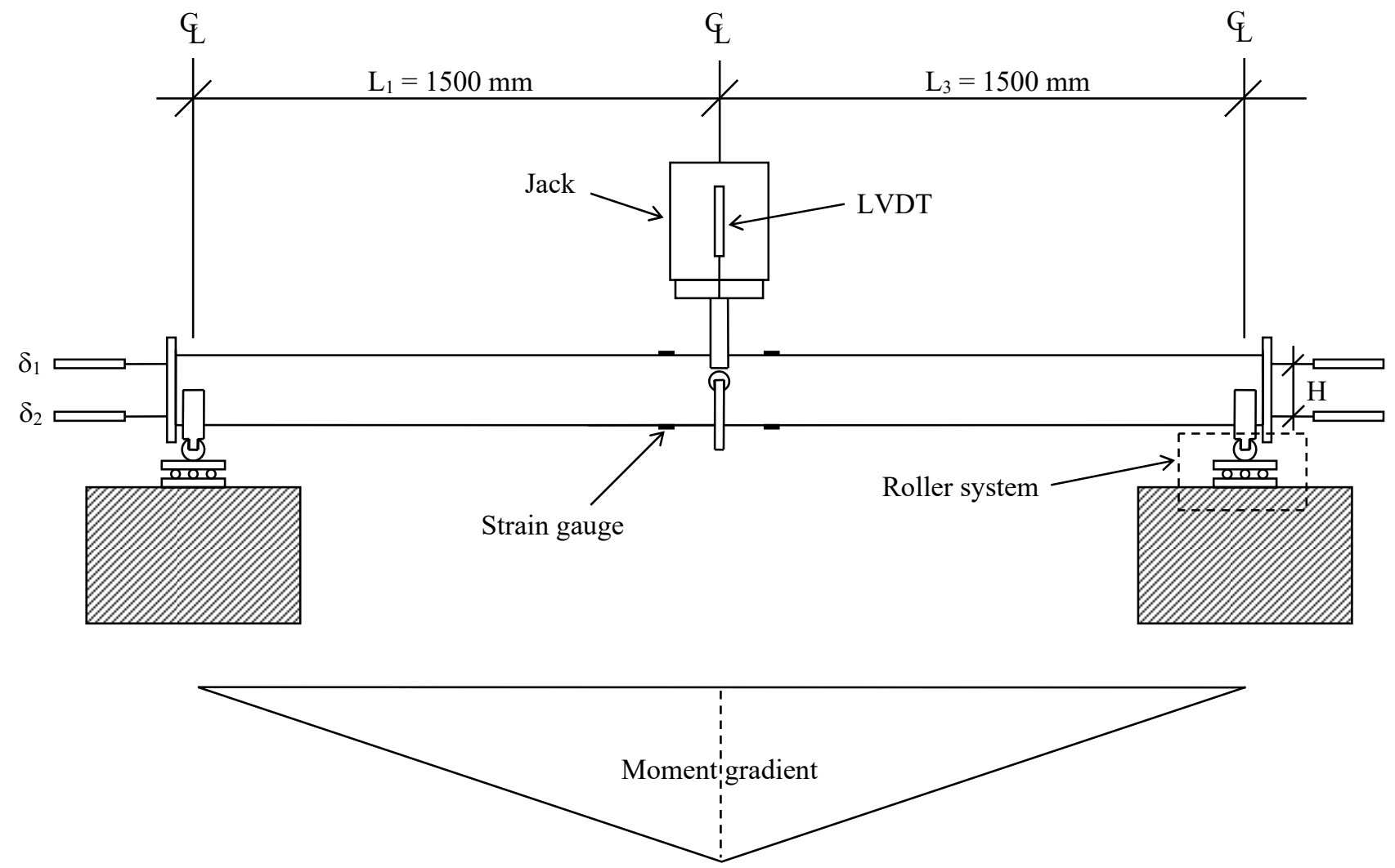

(a) Schematic setup

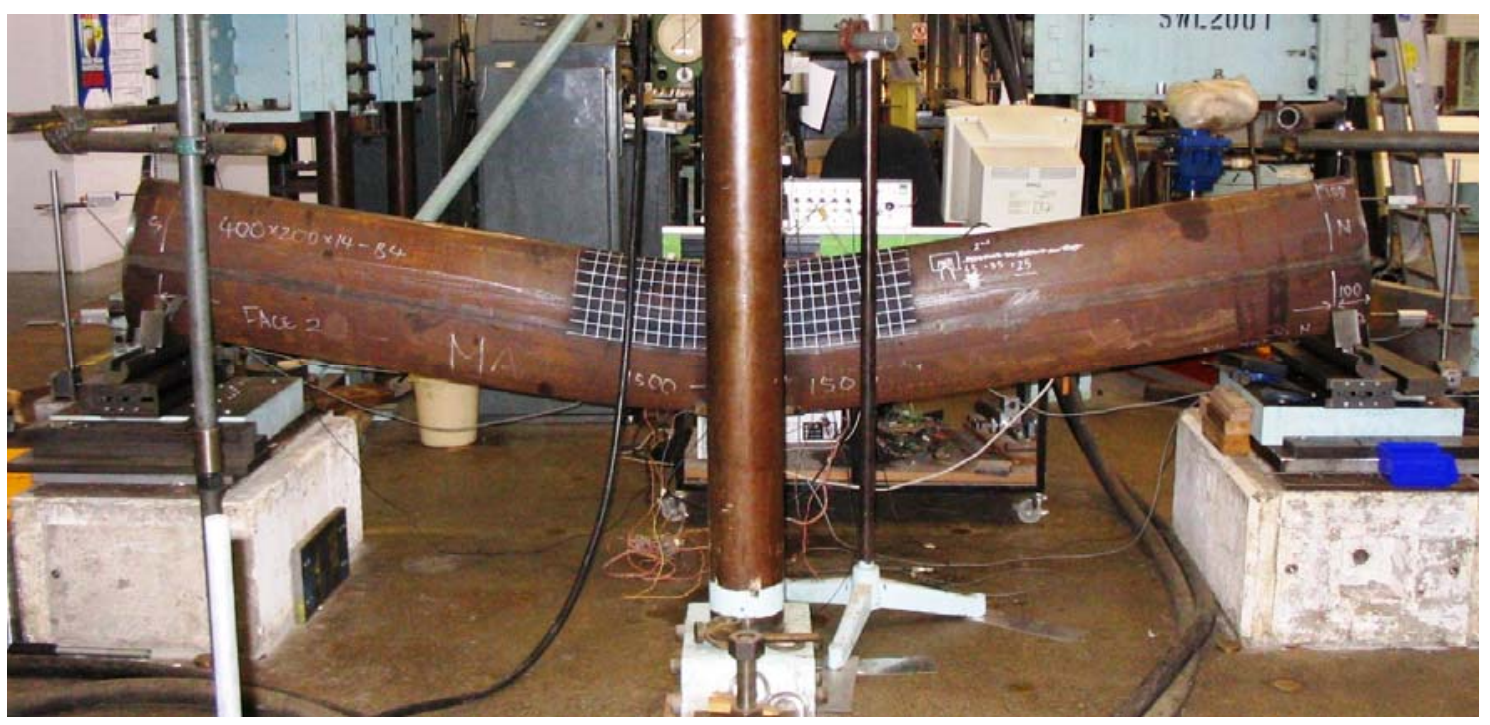

(b) Experimental setup

Fig. 7. Three-point bending tests. 


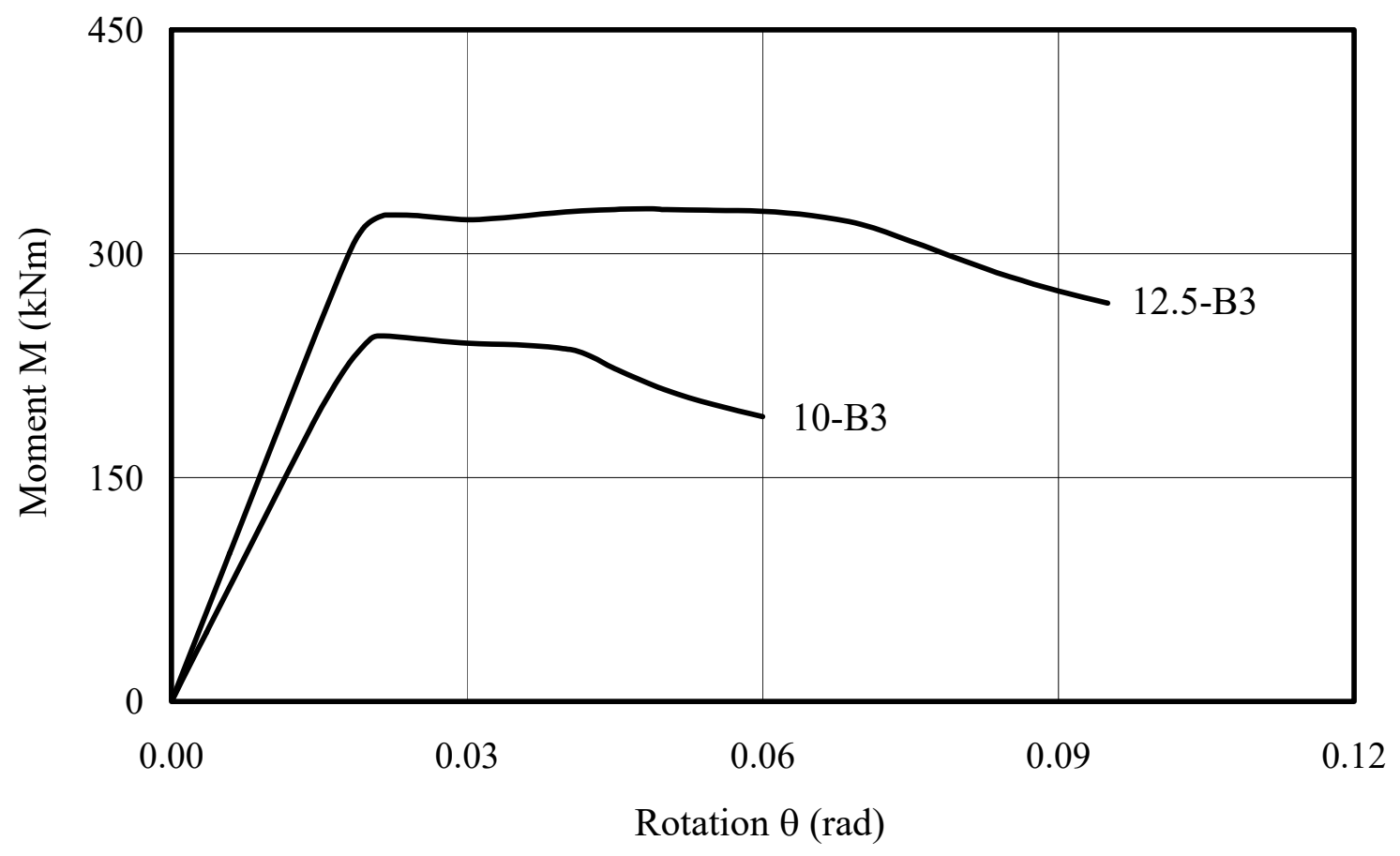

Fig. 8. Moment-rotation responses of $400 \times 200$ beams in three-point minor axis bending.

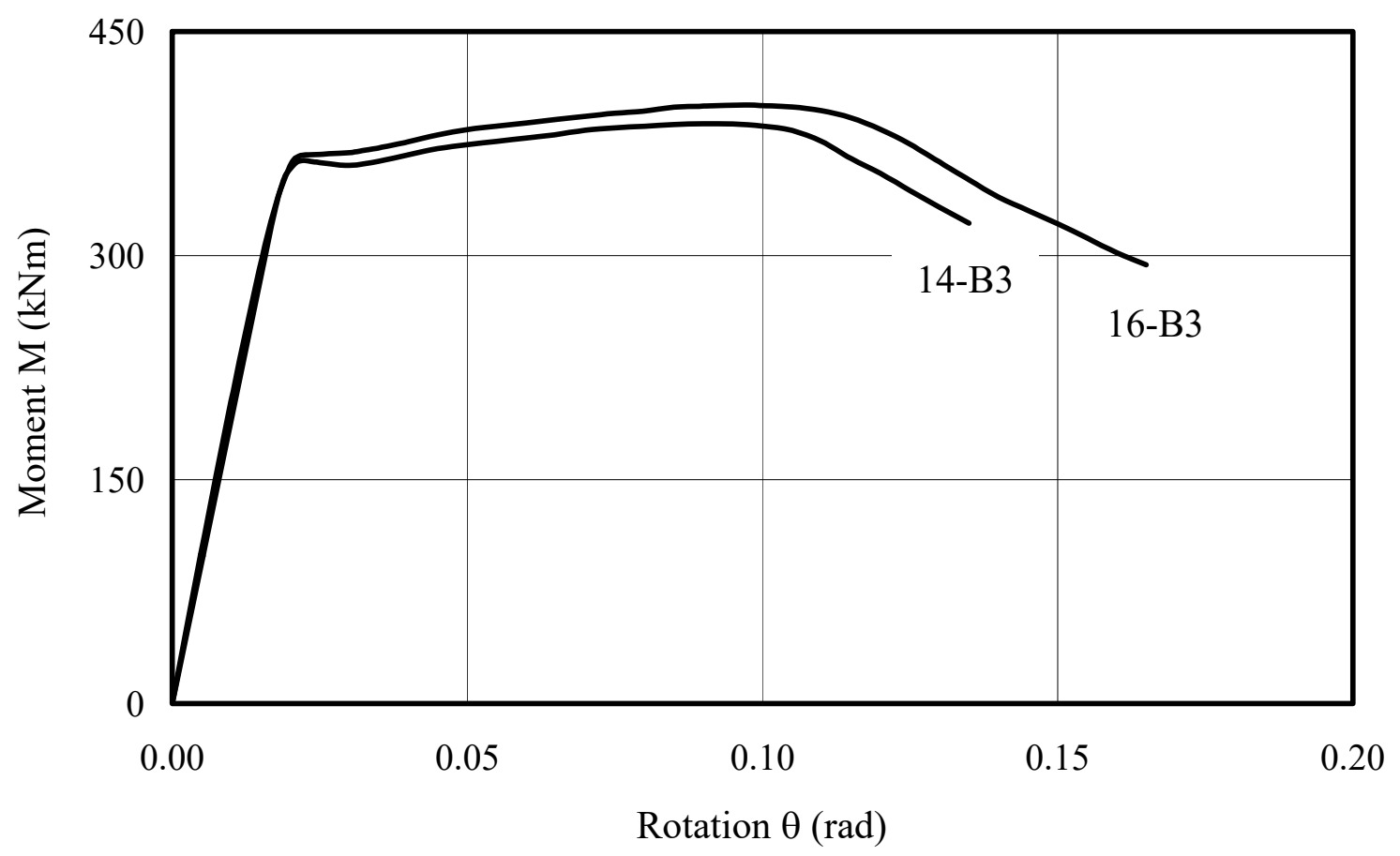

Fig. 9. Moment-rotation responses of $400 \times 200$ beams in three-point minor axis bending. 


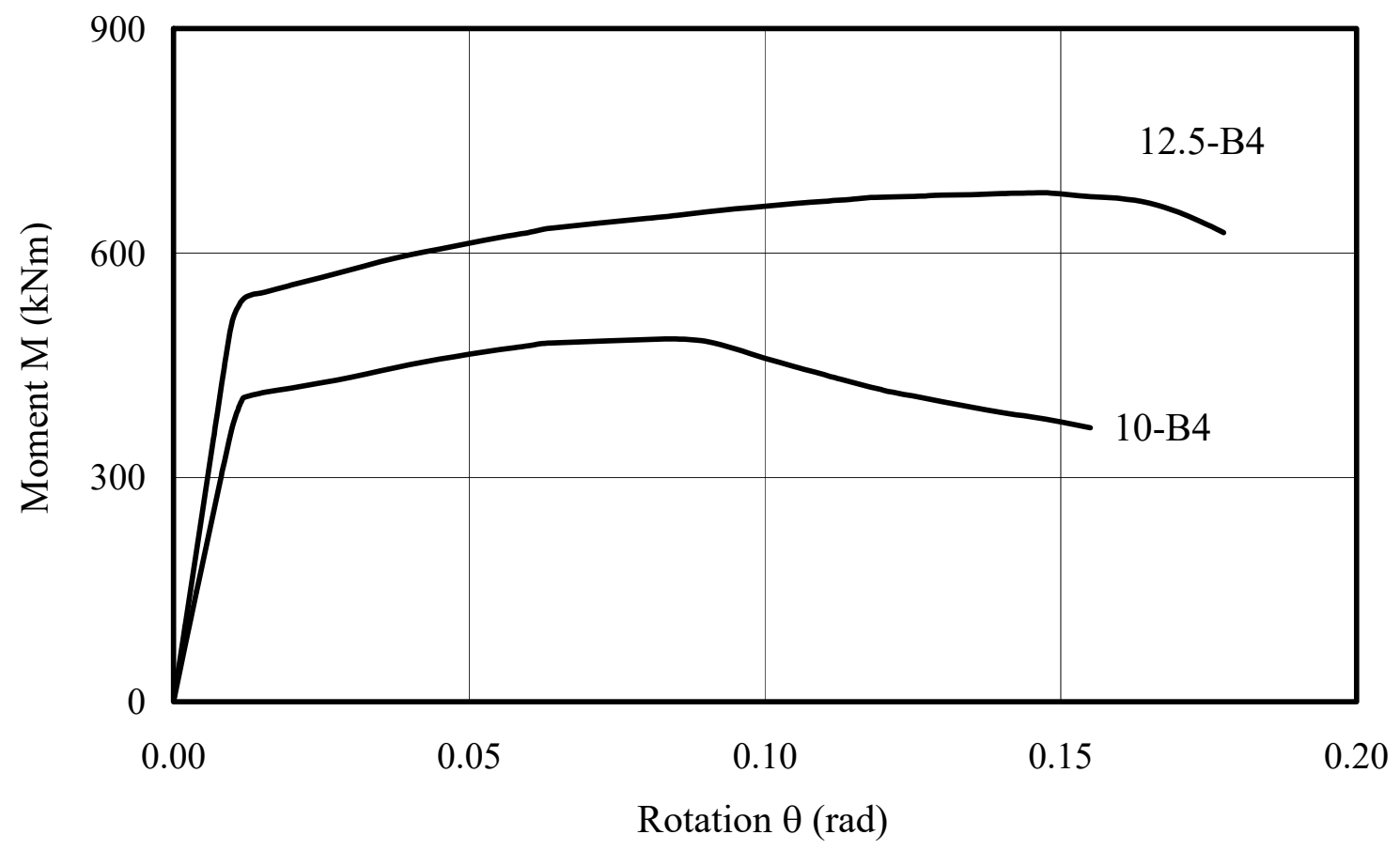

Fig. 10. Moment-rotation responses of $400 \times 200$ beams in three-point major axis bending.

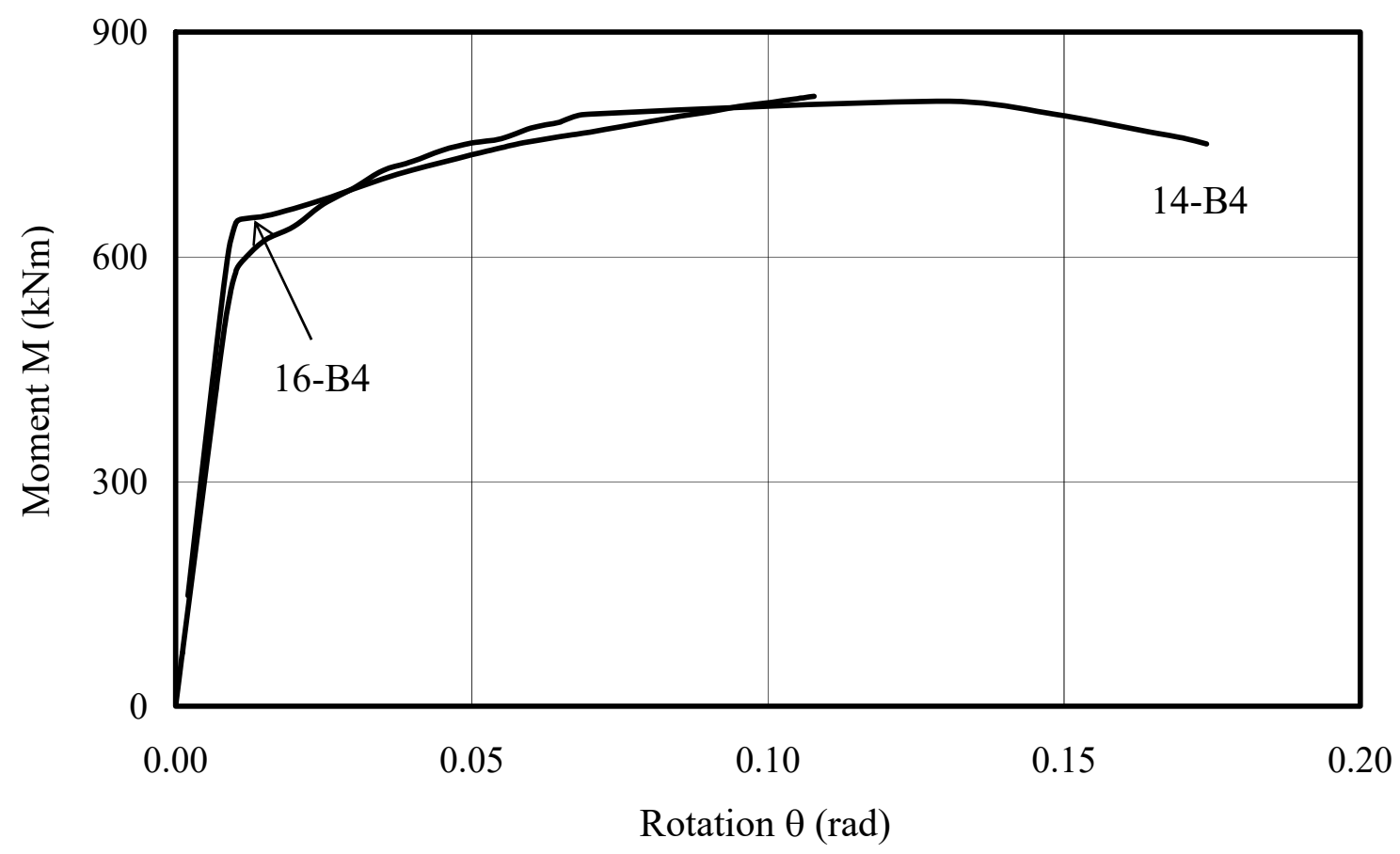

Fig. 11. Moment-rotation responses of $400 \times 200$ beams in three-point major axis bending. 

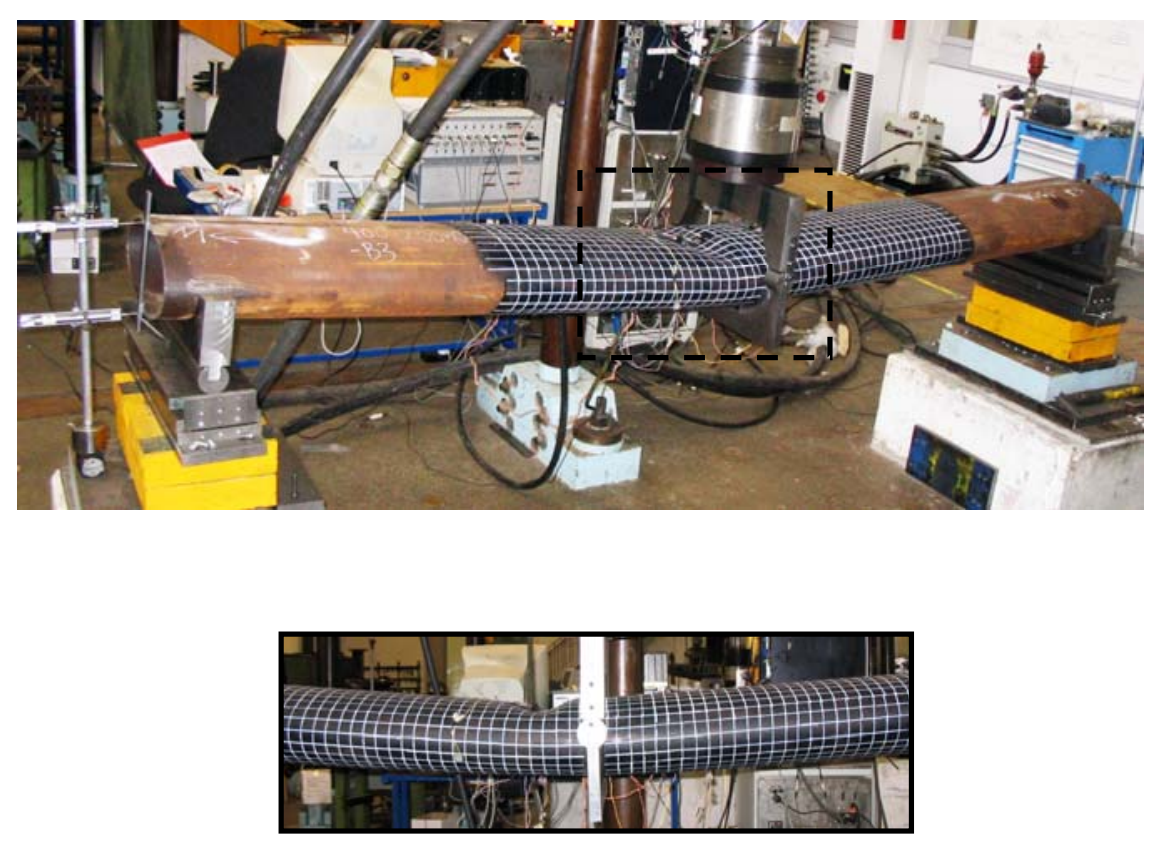

(a) Laboratory test
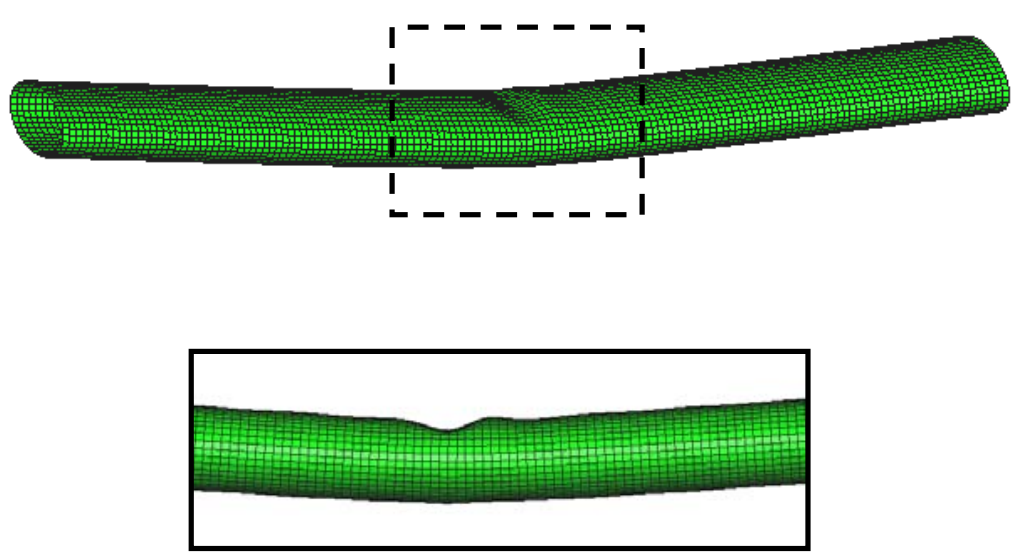

(b) Numerical model

Fig. 12. Typical Failure mode $(400 \times 200 \times 10.0-\mathrm{B} 3$ beam $)$. 


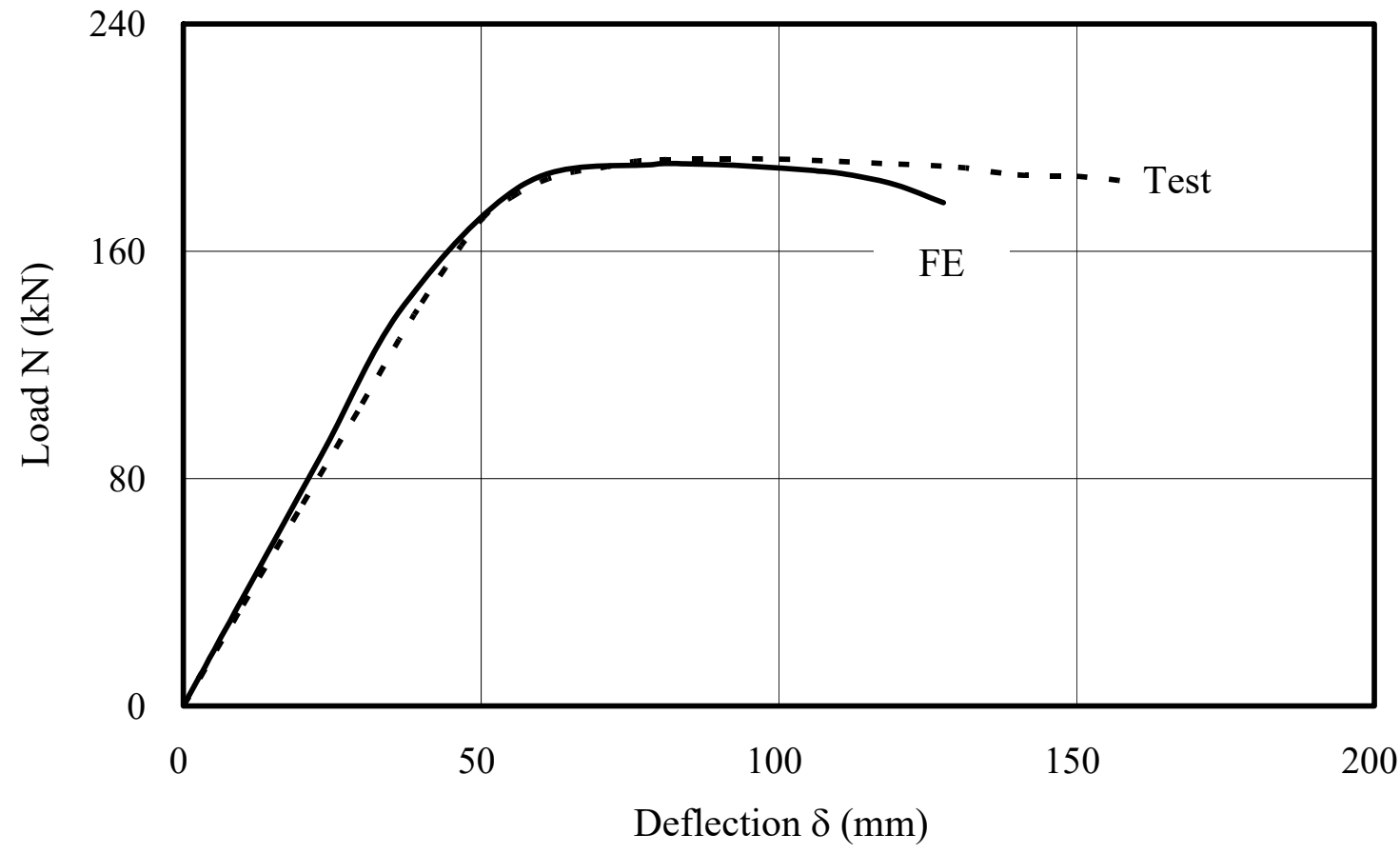

Fig. $13.400 \times 200 \times 12.5-\mathrm{B} 1$ beam load-midspan deflection curves $(\mathrm{FE}-$ Imperfection $=\mathrm{t} / 10)$.

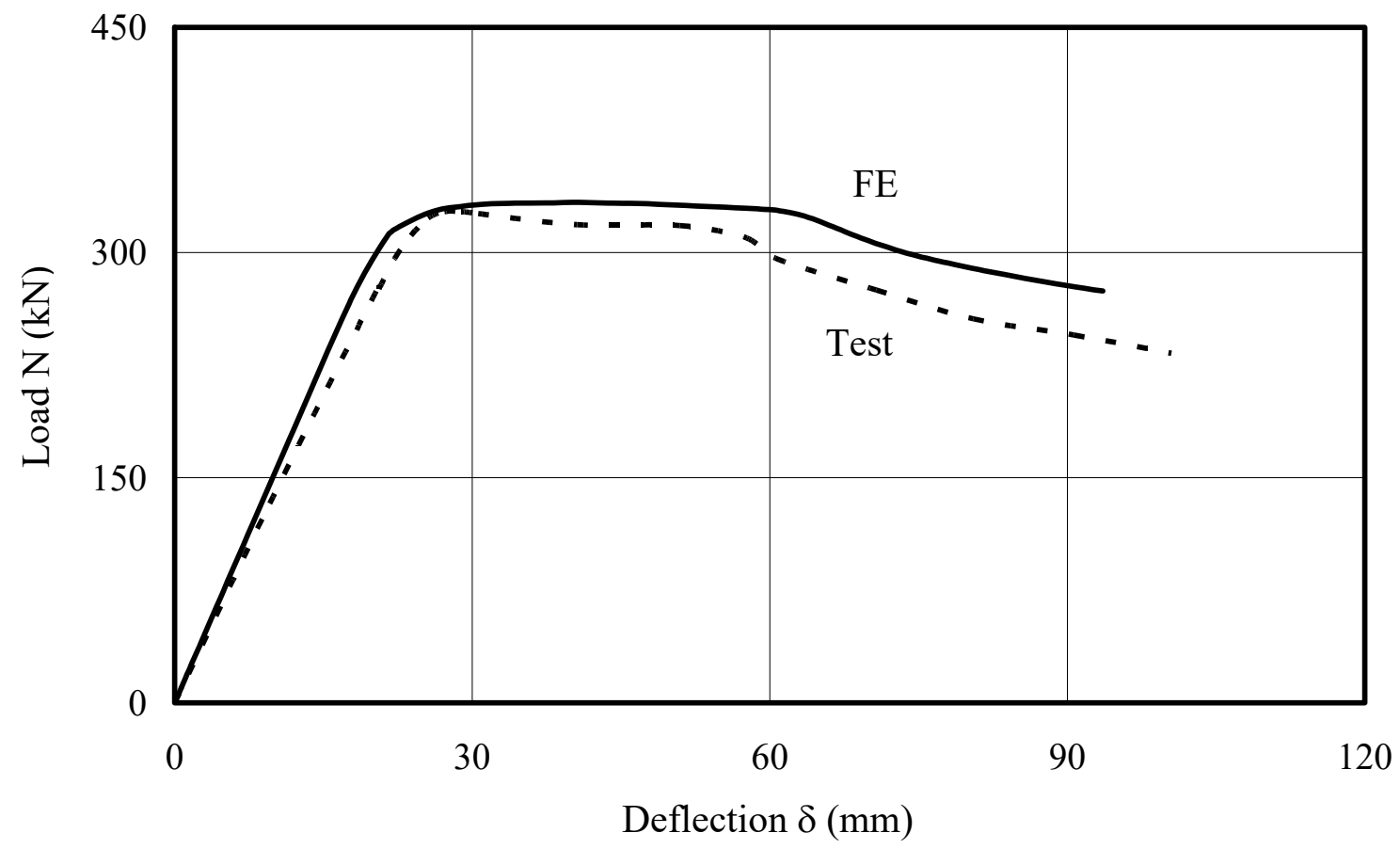

Fig. 14. $400 \times 200 \times 10.0-\mathrm{B} 3$ beam load-midspan deflection curves $(\mathrm{FE}-$ Imperfection $=\mathrm{t} / 10)$. 


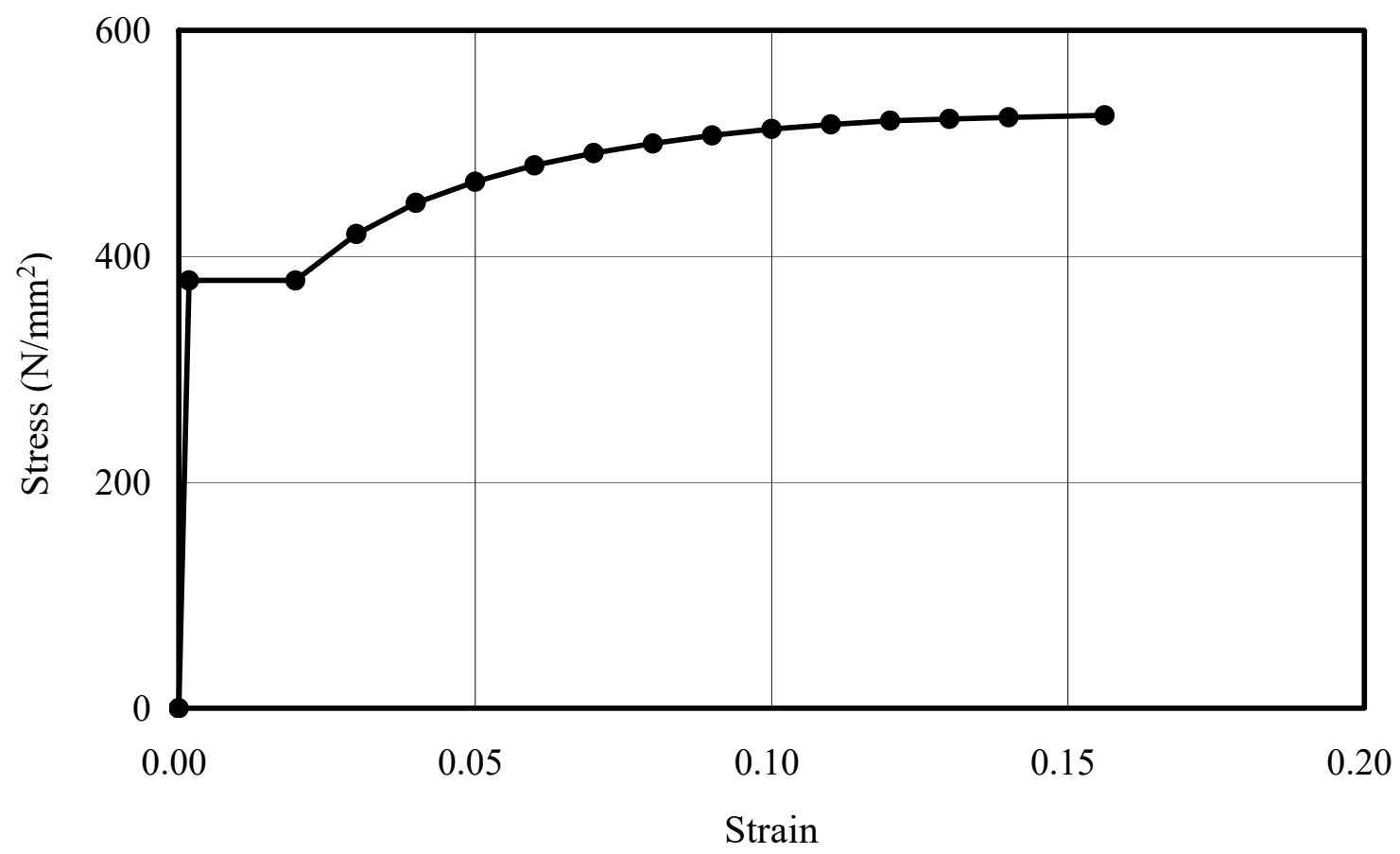

Fig. 15. Piecewise linear stress-strain model. 


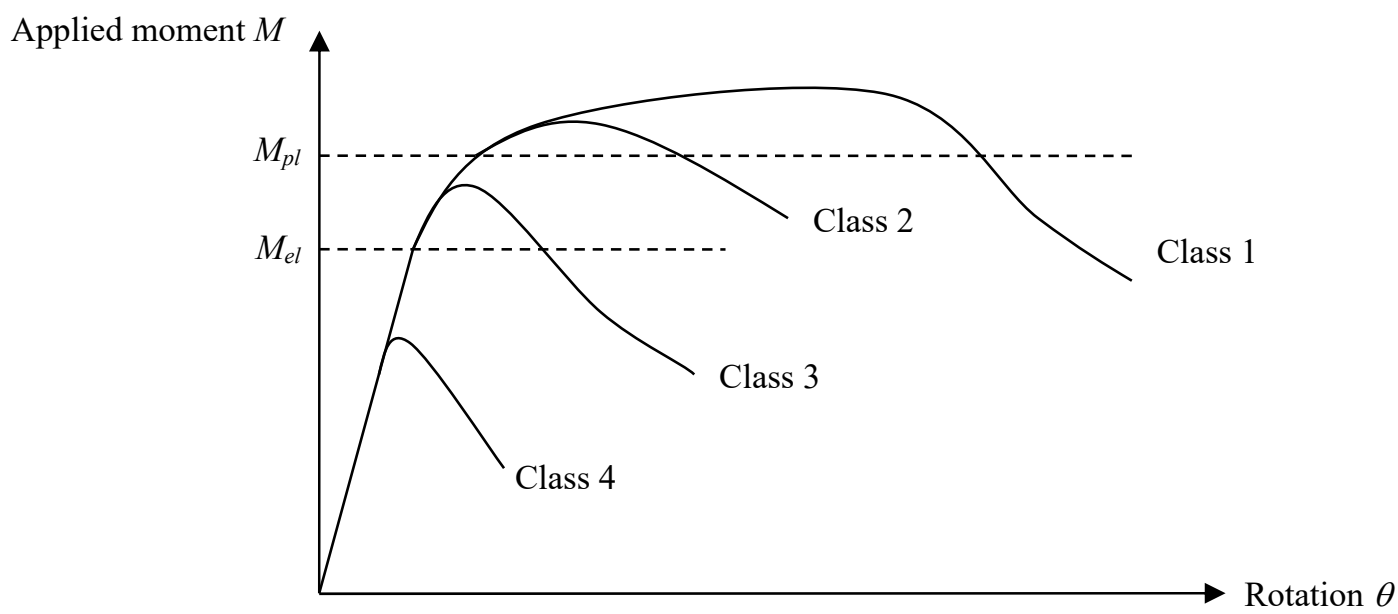

Fig. 16. Four behavioural classes of cross-section. 


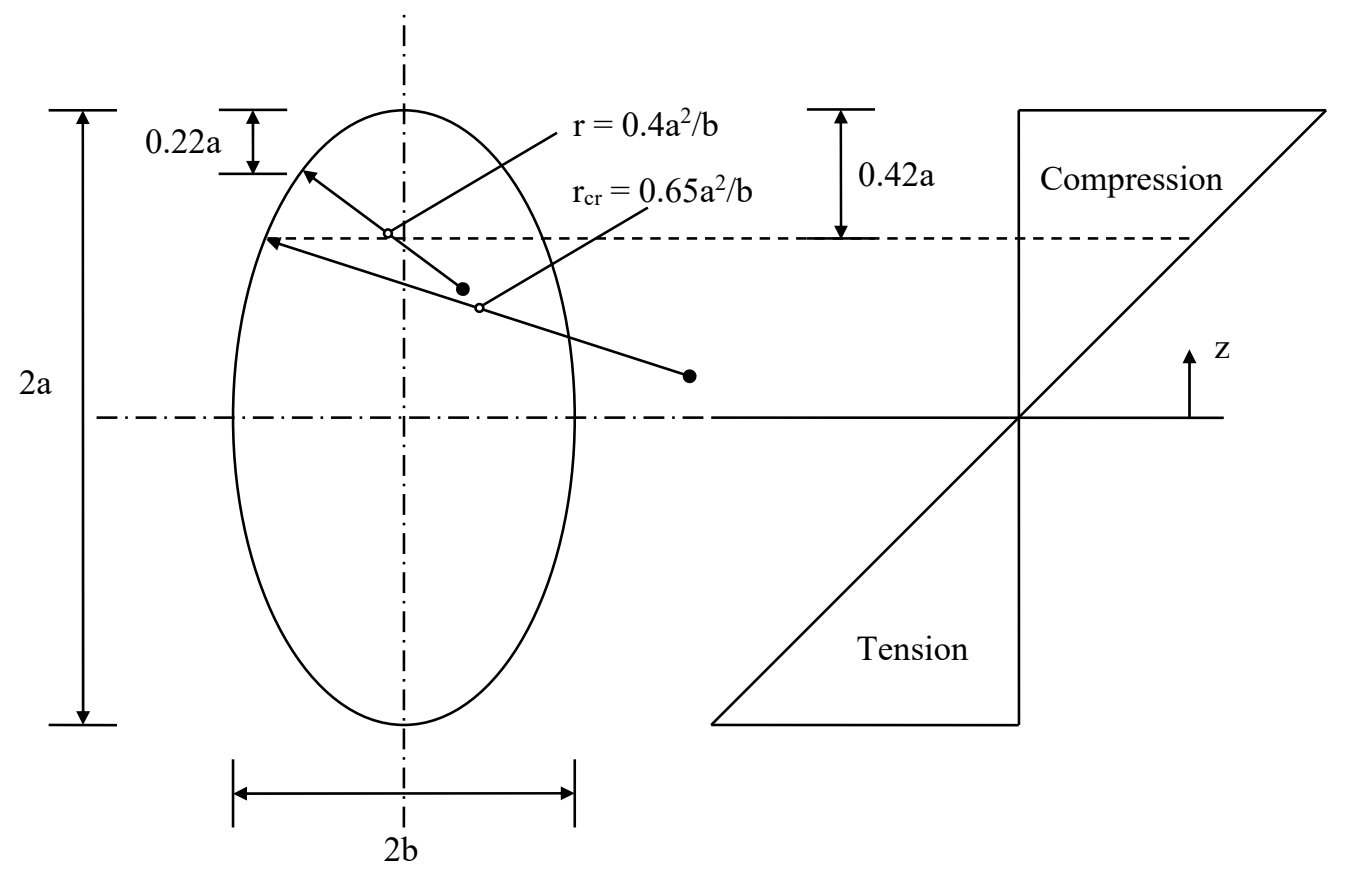

Fig. 17. Location of critical radius of curvature in elastic major axis bending. 


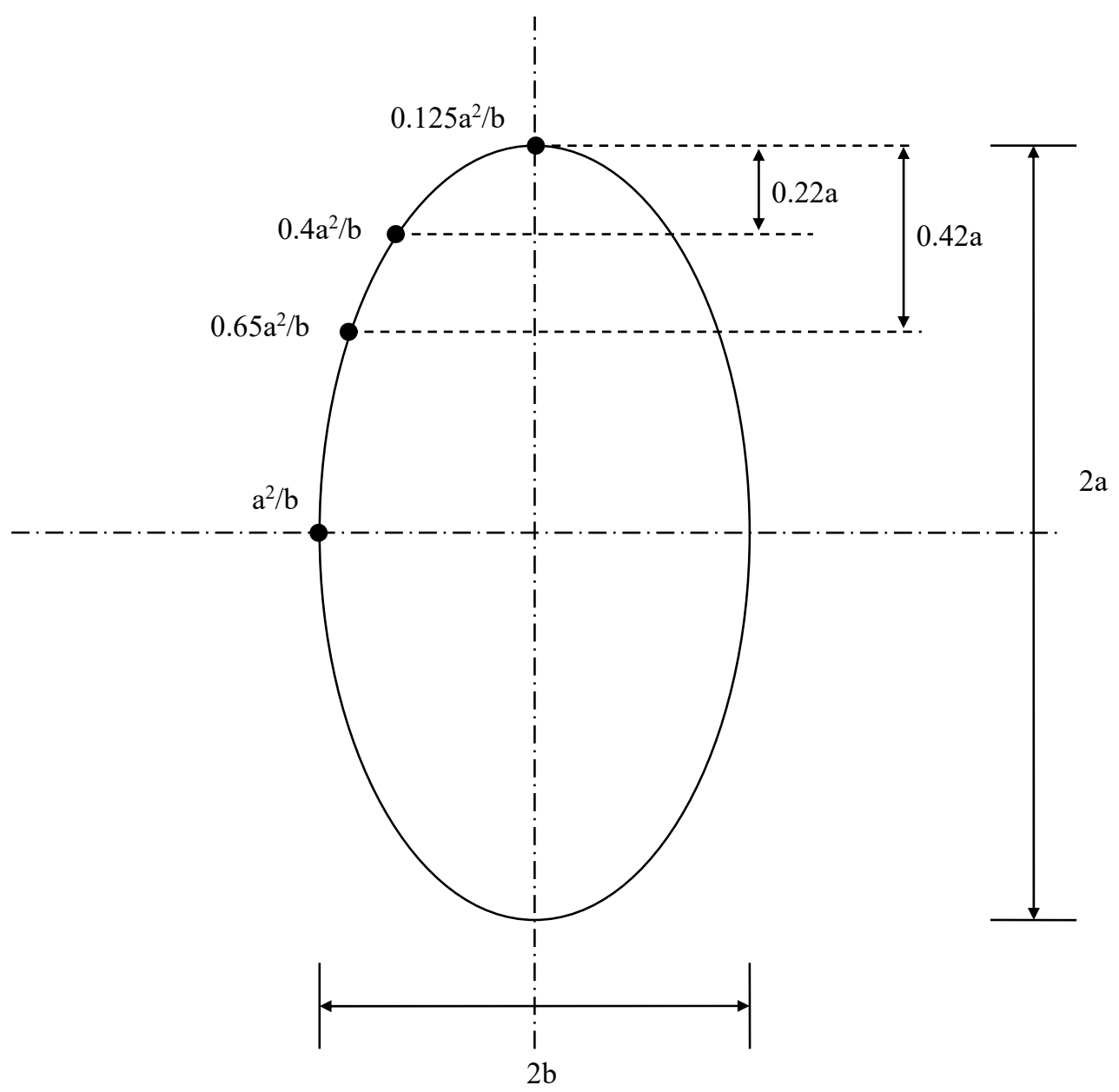

Fig. 18. Radii of curvature at different positions (aspect ratio $a / b=2$ ). 


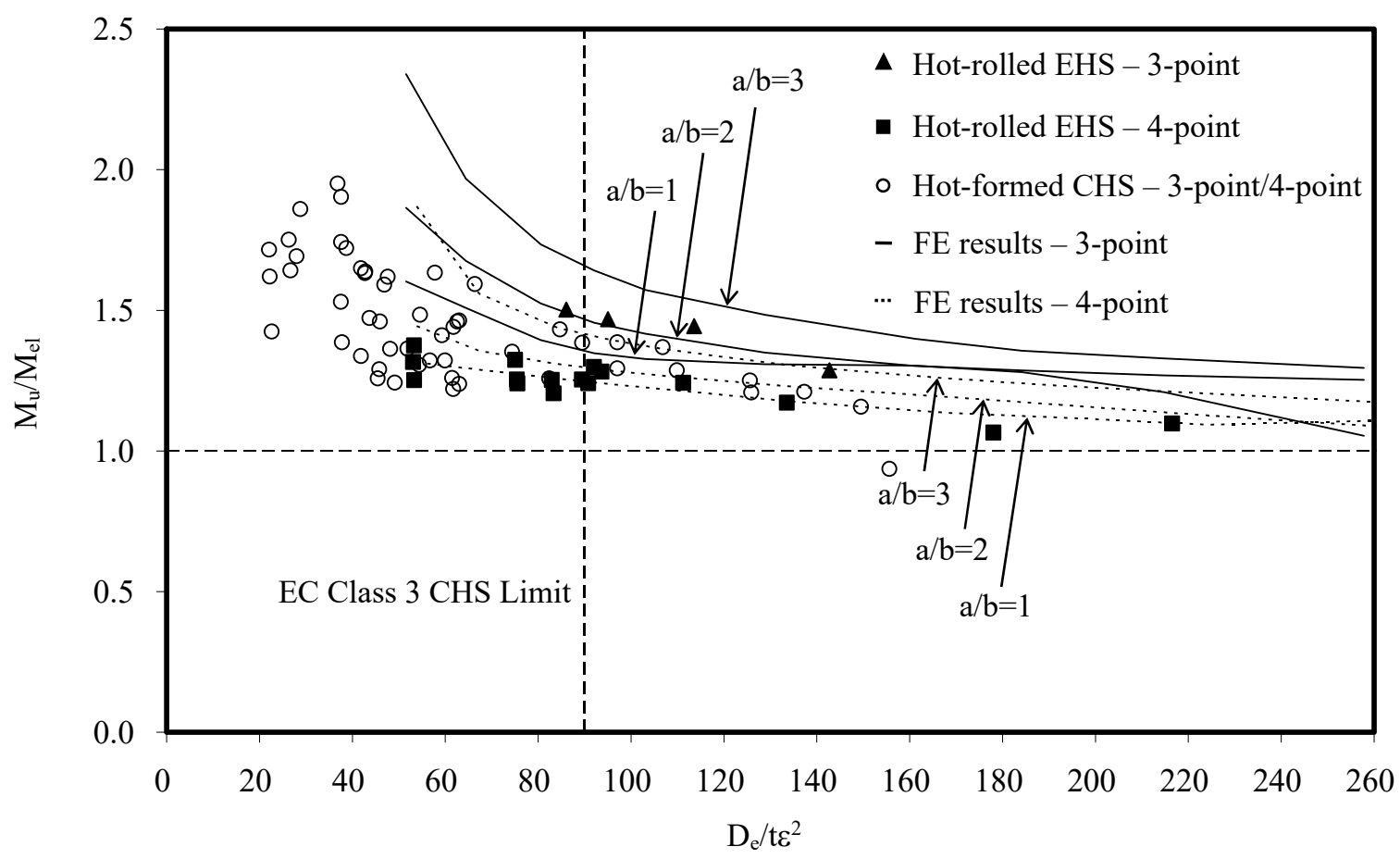

Fig. 19. $\mathrm{Mu} / \mathrm{Mel}$ versus cross-section slenderness (minor axis bending).

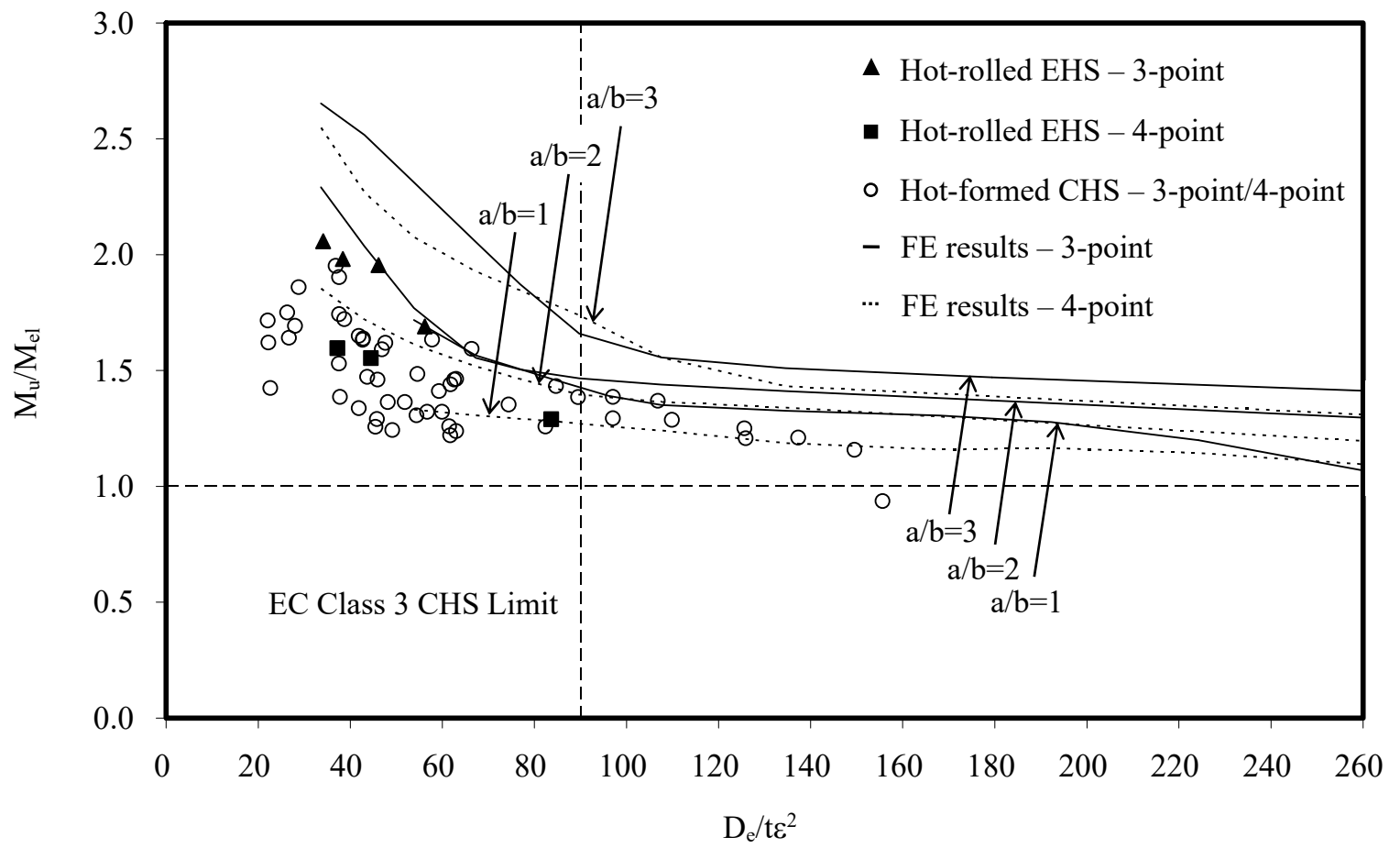

Fig. 20. $\mathrm{M}_{\mathrm{u}} / \mathrm{Mel}_{\mathrm{el}}$ versus cross-section slenderness (major axis bending). 


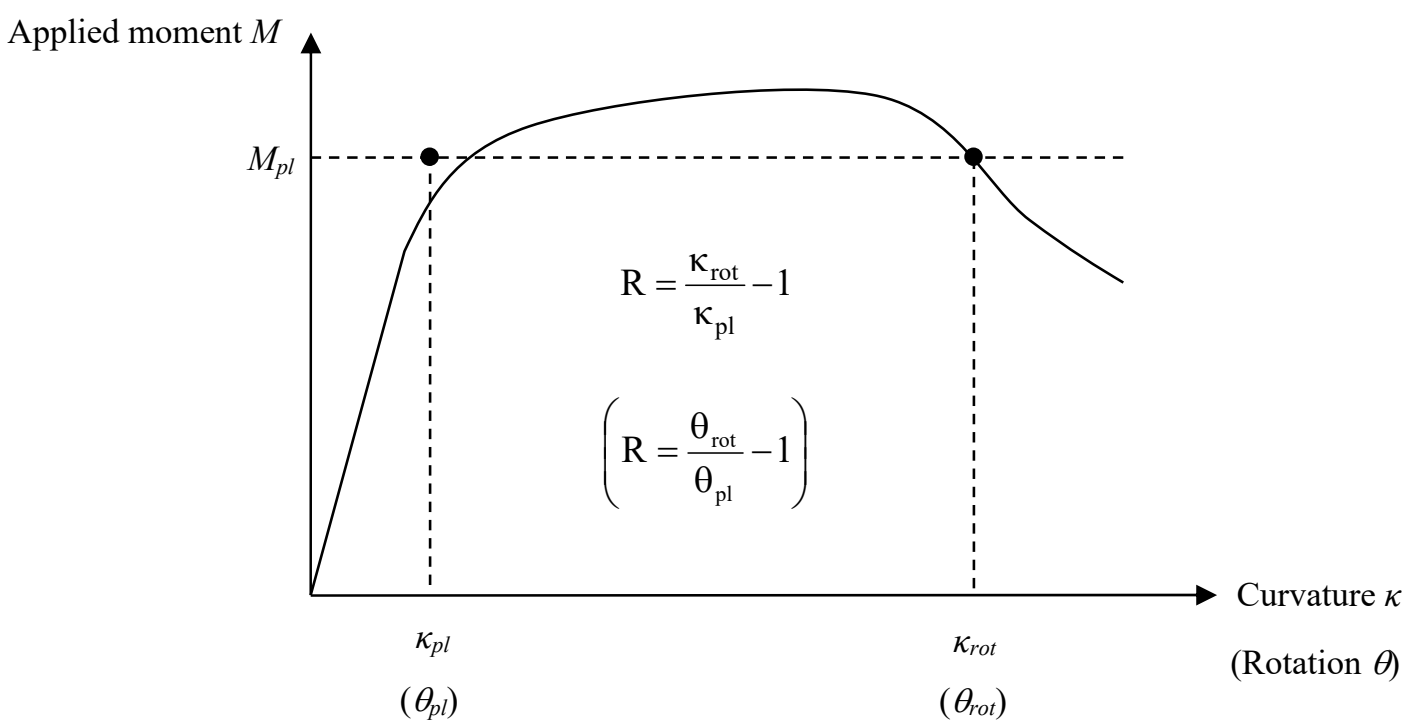

Fig. 21. Definition of rotation capacity from moment-curvature and moment-rotation graphs. 


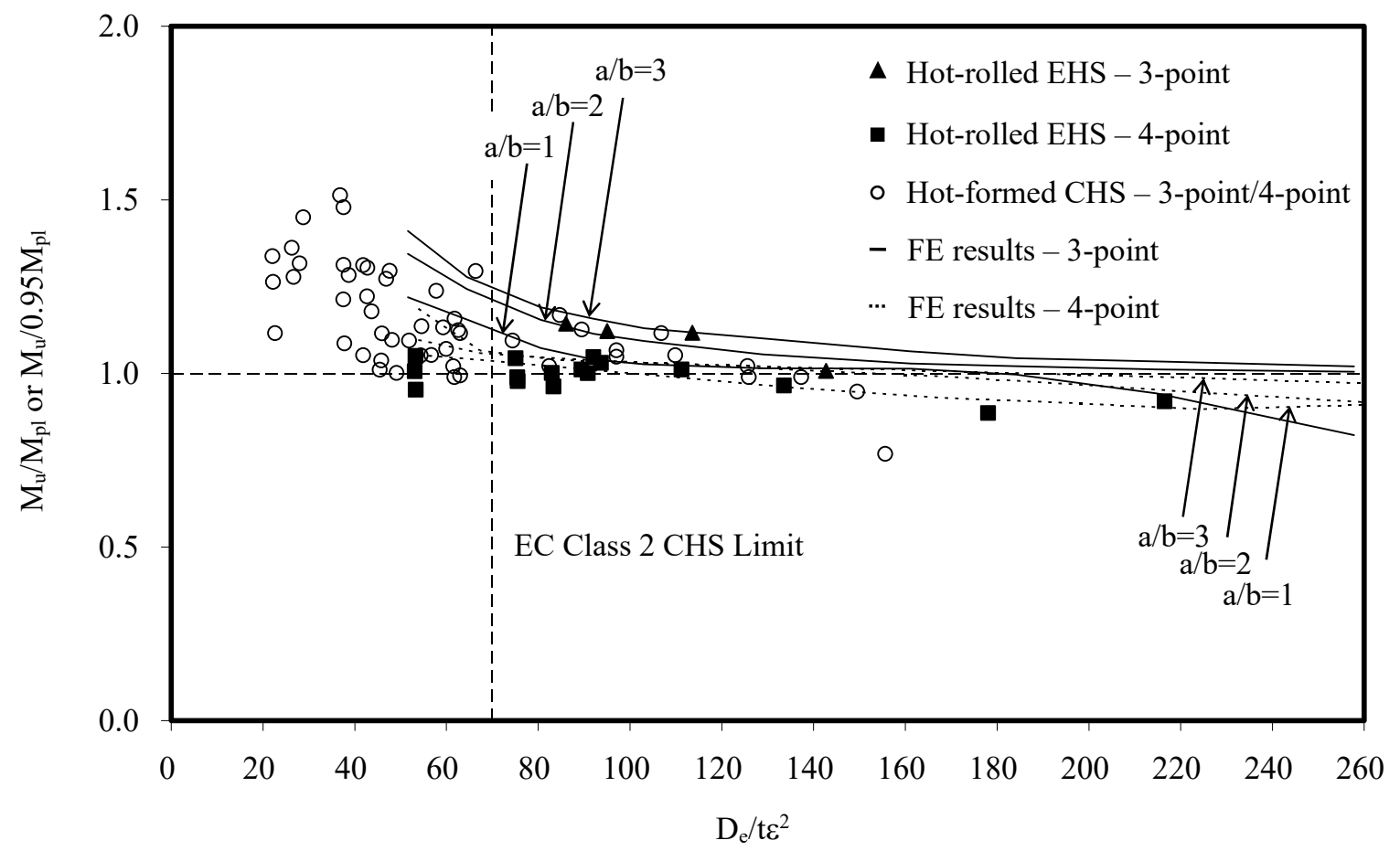

Note: $0.95 M_{p l}$ for 4-point bending test results

Fig. 22. $\mathrm{M}_{\mathrm{u}} / \mathrm{M}_{\mathrm{pl}}$ or $\mathrm{M}_{\mathrm{u}} / 0.95 \mathrm{M}_{\mathrm{pl}}$ versus cross-section slenderness (minor axis bending).

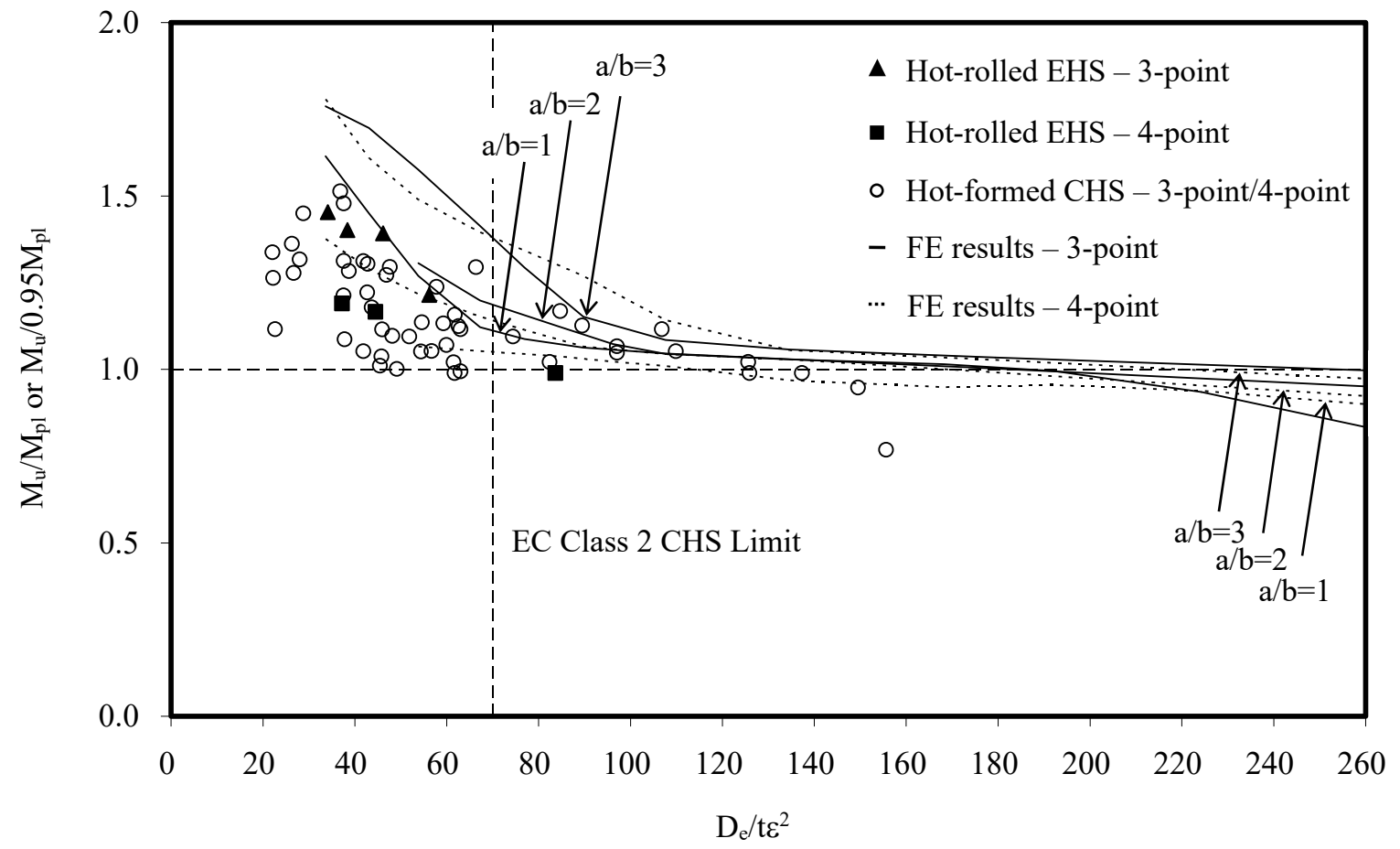

Note: $\quad 0.95 M_{p l}$ for 4-point bending test results

Fig. 23. $\mathrm{M}_{\mathrm{u}} / \mathrm{M}_{\mathrm{pl}}$ or $\mathrm{M}_{\mathrm{u}} / 0.95 \mathrm{M}_{\mathrm{pl}}$ versus cross-section slenderness (major axis bending). 


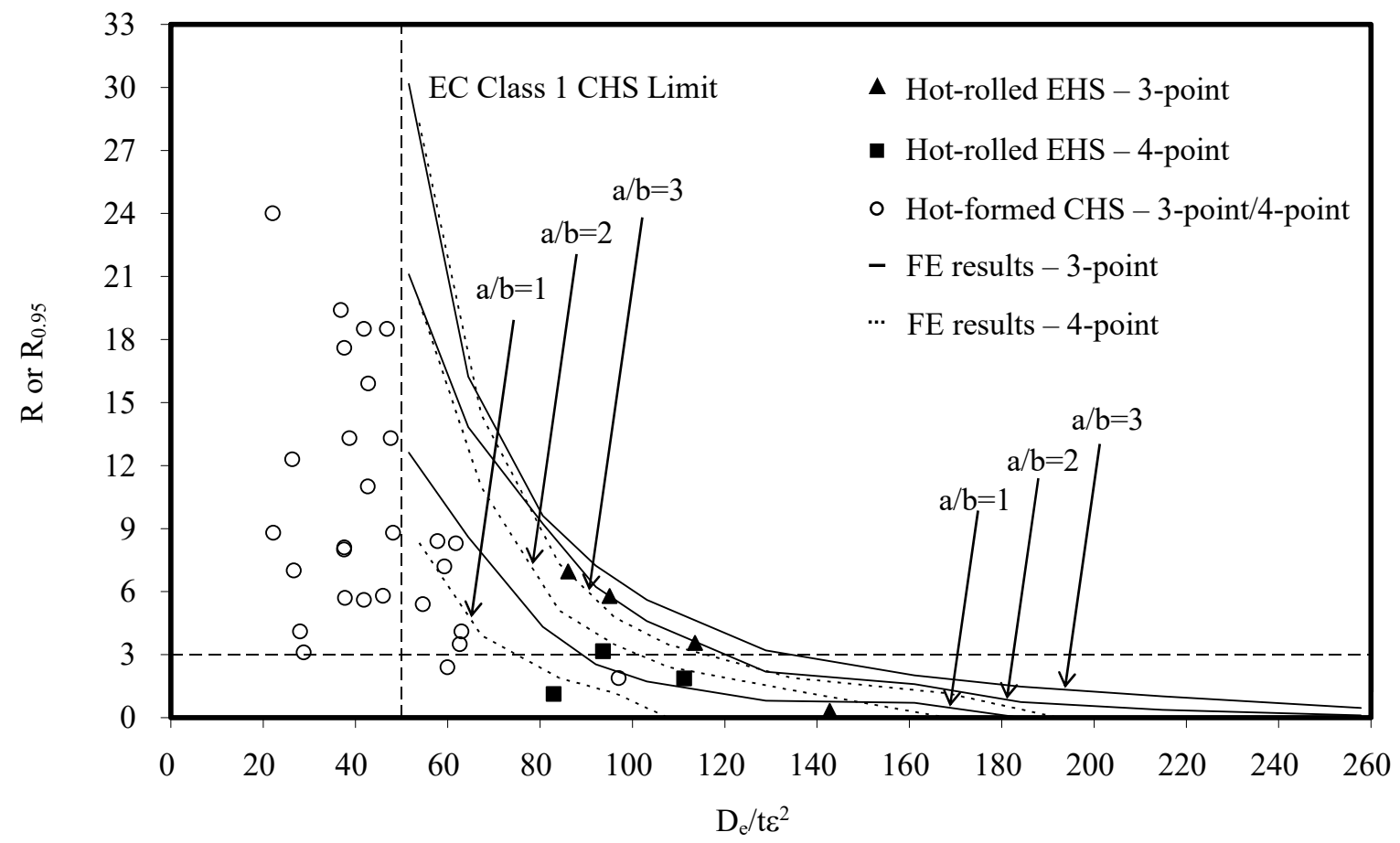

Note: $\quad R$ evaluated based on $M_{p l}$

$R_{0.95}$ evaluated based on $0.95 M_{\text {pl }}$ for 4-point bending test results

$R$ from hot-formed CHS based on $M_{p l}$

Fig. 24. Rotation capacity versus cross-section slenderness (minor axis bending).

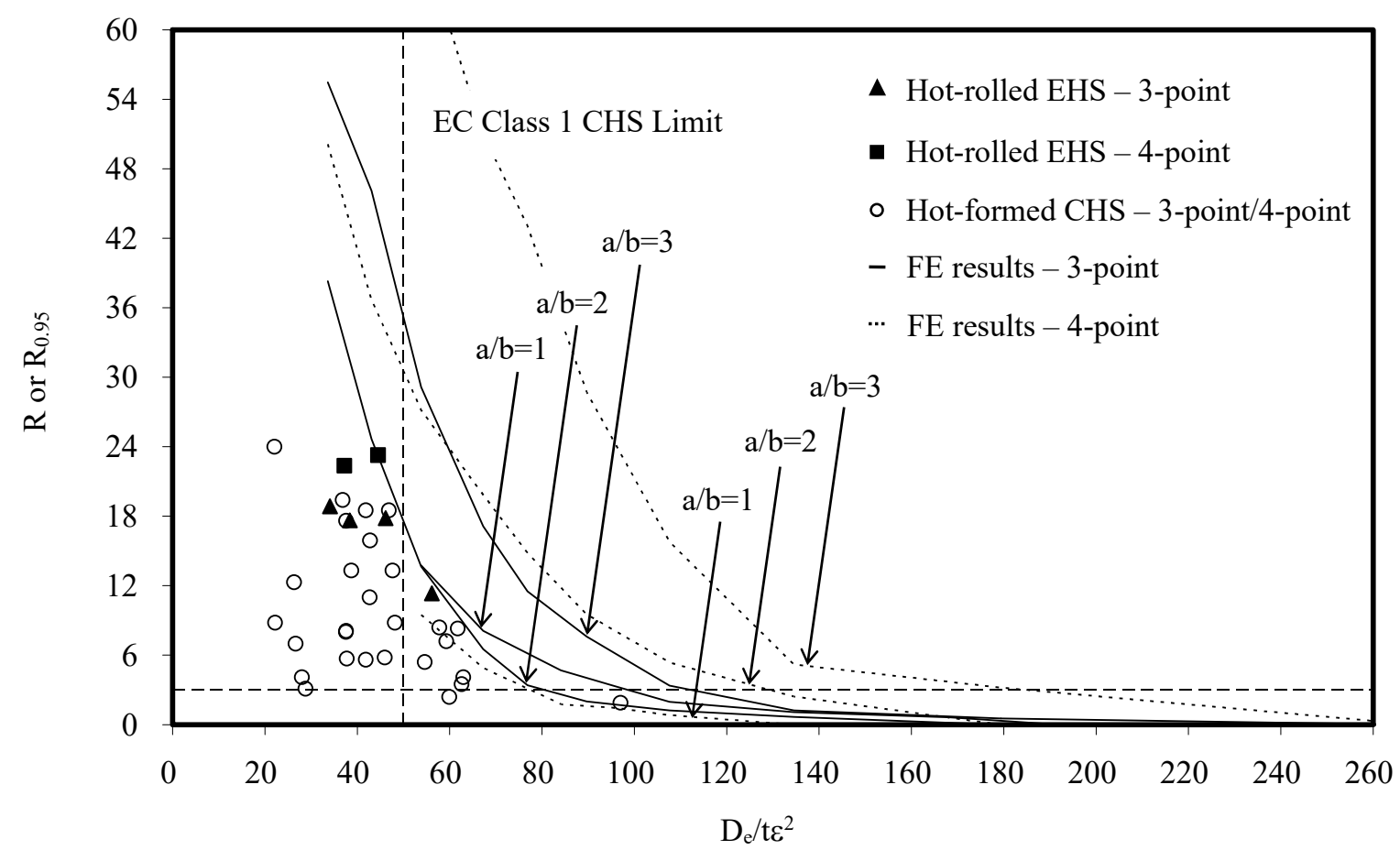

Note: $\quad R$ evaluated based on $M_{p l}$

$R_{0.95}$ evaluated based on $0.95 M_{\text {pl }}$ for 4-point bending test results

$R$ from hot-formed CHS based on $M_{p l}$

Fig. 25. Rotation capacity versus cross-section slenderness (major axis bending). 
Table 1 Mean measured dimensions and key results from the tensile coupons tests

\begin{tabular}{cccccc}
\hline Tensile coupons & $\begin{array}{c}\text { Width } \\
\mathrm{b}_{\mathrm{tc}} \\
(\mathrm{mm})\end{array}$ & $\begin{array}{c}\text { Thickness } \\
\mathrm{t} \\
(\mathrm{mm})\end{array}$ & $\begin{array}{c}\text { Young's } \\
\text { modulus } \\
\mathrm{E} \\
\left(\mathrm{N} / \mathrm{mm}^{2}\right)\end{array}$ & $\begin{array}{c}\text { Yield stress } \\
\sigma_{\mathrm{y}} \\
\left(\mathrm{N} / \mathrm{mm}^{2}\right)\end{array}$ & $\begin{array}{c}\text { Ultimate } \\
\text { tensile stress } \\
\sigma_{\mathrm{u}} \\
\left(\mathrm{N} / \mathrm{mm}^{2}\right)\end{array}$ \\
\hline $400 \times 200 \times 8.0-\mathrm{TC} 1$ & 29.60 & 7.53 & 222000 & 434 & 559 \\
$400 \times 200 \times 8.0-\mathrm{TC} 2$ & 29.60 & 7.62 & 221200 & 424 & 541 \\
$400 \times 200 \times 10.0-\mathrm{TC} 1$ & 30.05 & 9.52 & 191800 & 396 & 527 \\
$400 \times 200 \times 10.0-\mathrm{TC} 2$ & 30.07 & 9.54 & 202400 & 406 & 540 \\
$400 \times 200 \times 12.5-\mathrm{TC} 1$ & 29.25 & 12.03 & 215200 & 388 & 525 \\
$400 \times 200 \times 12.5-\mathrm{TC} 2$ & 29.26 & 11.98 & 215000 & 402 & 544 \\
$400 \times 200 \times 14.0-\mathrm{TC} 1$ & 29.49 & 14.34 & 220100 & 387 & 533 \\
$400 \times 200 \times 14.0-\mathrm{TC} 2$ & 29.55 & 14.33 & 220100 & 408 & 535 \\
$400 \times 200 \times 16.0-\mathrm{TC} 1$ & 29.98 & 15.13 & 221200 & 377 & 531 \\
$400 \times 200 \times 16.0-\mathrm{TC} 2$ & 30.00 & 15.33 & 221300 & 380 & 519 \\
\hline $500 \times 250 \times 8.0-\mathrm{TC} 1$ & 29.72 & 7.59 & 219900 & 409 & 532 \\
$500 \times 250 \times 8.0-\mathrm{TC} 2$ & 29.57 & 7.56 & 227700 & 417 & 540 \\
\hline
\end{tabular}


Table 2 Mean measured dimensions of bending specimens

\begin{tabular}{|c|c|c|c|c|c|c|c|}
\hline Beams & Axis of bending & $\begin{array}{c}\text { Larger } \\
\text { outer diameter } \\
2 \mathrm{a} \\
(\mathrm{mm})\end{array}$ & $\begin{array}{c}\text { Smaller } \\
\text { outer diameter } \\
2 \mathrm{~b} \\
(\mathrm{~mm})\end{array}$ & $\begin{array}{c}\text { Thickness } \\
\mathrm{t} \\
(\mathrm{mm})\end{array}$ & $\begin{array}{c}\text { Elastic section } \\
\text { modulus } \\
\mathrm{W}_{\mathrm{el}} \\
\left(\mathrm{mm}^{3}\right)\end{array}$ & $\begin{array}{c}\text { Plastic section } \\
\text { modulus } \\
\mathrm{W}_{\mathrm{pl}} \\
\left(\mathrm{mm}^{3}\right)\end{array}$ & $\begin{array}{c}\text { Measured } \\
\text { maximum local } \\
\text { imperfection } \\
\omega_{0} \\
(\mathrm{~mm}) \\
\end{array}$ \\
\hline $400 \times 200 \times 8.0-B 1$ & Minor & 396.09 & 207.63 & 7.75 & 407800 & 516100 & 0.43 \\
\hline $400 \times 200 \times 10.0-B 1$ & Minor & 396.06 & 207.54 & 9.65 & 495200 & 632600 & 1.14 \\
\hline $400 \times 200 \times 12.5-B 1$ & Minor & 401.54 & 201.01 & 12.13 & 587100 & 759200 & 2.92 \\
\hline $400 \times 200 \times 14.0-B 1$ & Minor & 400.32 & 200.04 & 14.48 & 672900 & 881100 & 3.69 \\
\hline $400 \times 200 \times 16.0-\mathrm{B} 1 \mathrm{a}$ & Minor & 403.16 & 201.08 & 15.63 & 724700 & 954200 & 0.57 \\
\hline $400 \times 200 \times 16.0-B 1 b$ & Minor & 403.28 & 202.15 & 15.63 & 729700 & 960700 & 0.74 \\
\hline $500 \times 250 \times 8.0-\mathrm{B} 1$ & Minor & 495.34 & 255.85 & 7.78 & 642000 & 806400 & 2.01 \\
\hline $400 \times 200 \times 12.5-B 2$ & Major & 401.34 & 200.77 & 12.13 & 892800 & 1252300 & 1.51 \\
\hline $400 \times 200 \times 14.0-B 2$ & Major & 399.90 & 201.06 & 14.48 & 1038000 & 1465200 & 0.49 \\
\hline $500 \times 250 \times 8.0-\mathrm{B} 2$ & Major & 491.74 & 260.92 & 7.78 & 933500 & 1281300 & 0.47 \\
\hline $400 \times 200 \times 10.0-B 3$ & Minor & 400.52 & 199.40 & 9.61 & 475300 & 606900 & 3.01 \\
\hline $400 \times 200 \times 12.5-B 3$ & Minor & 402.24 & 200.10 & 11.98 & 578600 & 747700 & 1.01 \\
\hline $400 \times 200 \times 14.0-B 3$ & Minor & 400.50 & 199.21 & 14.34 & 664600 & 869700 & 0.75 \\
\hline $400 \times 200 \times 16.0-B 3$ & Minor & 403.35 & 199.49 & 15.27 & 704600 & 926300 & 0.93 \\
\hline $400 \times 200 \times 10.0-B 4$ & Major & 399.02 & 202.06 & 9.57 & 716500 & 996800 & 2.49 \\
\hline $400 \times 200 \times 12.5-B 4$ & Major & 403.08 & 198.53 & 11.94 & 881200 & 1237100 & 2.24 \\
\hline $400 \times 200 \times 14.0-B 4$ & Major & 400.90 & 197.82 & 14.34 & 1024900 & 1448600 & 1.09 \\
\hline $400 \times 200 \times 16.0-B 4$ & Major & 403.53 & 200.72 & 15.33 & 1105900 & 1565800 & 1.10 \\
\hline
\end{tabular}


Table 3 Summary of results from the in-plane bending tests

\begin{tabular}{|c|c|c|c|c|c|}
\hline Beams & Axis of bending & $\begin{array}{c}\text { Ultimate moment } \\
\mathrm{M}_{\mathrm{u}}(\mathrm{kNm})\end{array}$ & $\begin{array}{l}\text { Curvature at } \mathrm{M}_{\mathrm{u}} \\
\kappa_{\mathrm{u}}\left(\times 10^{-5} \mathrm{~mm}^{-1}\right)\end{array}$ & $\begin{array}{c}\text { Rotation at } \mathrm{M}_{\mathrm{u}} \\
\theta_{\mathrm{u}}(\mathrm{rad}) \\
\end{array}$ & $\begin{array}{c}\text { Rotation capacity } \\
\text { R or } \mathrm{R}_{0.95} \\
\end{array}$ \\
\hline $400 \times 200 \times 8.0-B 1$ & Minor & 186 & 2.41 & - & - \\
\hline $400 \times 200 \times 10.0-\mathrm{B} 1$ & Minor & 232 & 3.59 & - & - \\
\hline $400 \times 200 \times 12.5-\mathrm{B} 1$ & Minor & 288 & 4.11 & - & 1.9 \\
\hline $400 \times 200 \times 14.0-\mathrm{B} 1$ & Minor & 343 & 5.04 & - & 3.2 \\
\hline $400 \times 200 \times 16.0-B 1 a$ & Minor & 331 & 4.33 & - & - \\
\hline $400 \times 200 \times 16.0-B 1 b$ & Minor & 346 & 3.85 & - & 1.1 \\
\hline $500 \times 250 \times 8.0-B 1$ & Minor & 291 & 1.73 & - & - \\
\hline $400 \times 200 \times 12.5-B 2$ & Major & 548 & 23.9 & - & 23.3 \\
\hline $400 \times 200 \times 14.0-\mathrm{B} 2$ & Major & 659 & 23.2 & - & $22.4^{*}$ \\
\hline $500 \times 250 \times 8.0-B 2$ & Major & 497 & 3.33 & - & - \\
\hline $400 \times 200 \times 10.0-B 3$ & Minor & 245 & - & 0.02 & 0.3 \\
\hline $400 \times 200 \times 12.5-B 3$ & Minor & 330 & - & 0.05 & 3.6 \\
\hline $400 \times 200 \times 14.0-B 3$ & Minor & 388 & - & 0.09 & 5.8 \\
\hline $400 \times 200 \times 16.0-\mathrm{B} 3$ & Minor & 401 & - & 0.10 & 7.0 \\
\hline $400 \times 200 \times 10.0-\mathrm{B} 4$ & Major & 485 & - & 0.08 & 11.4 \\
\hline $400 \times 200 \times 12.5-\mathrm{B} 4$ & Major & 681 & - & 0.15 & $17.8^{* *}$ \\
\hline $400 \times 200 \times 14.0-B 4$ & Major & 808 & - & 0.13 & $17.6^{* *}$ \\
\hline $400 \times 200 \times 16.0-B 4$ & Major & $862^{\#}$ & - & 0.17 & $18.9^{* *}$ \\
\hline
\end{tabular}

* $\quad$ test moment did not drop back to $0.95 \mathrm{M}_{\mathrm{pl}}$

** test moment did not drop back to $\mathrm{M}_{\mathrm{pl}}$

\# test did not reach the peak load 
Table 4 Comparison of the in-plane bending test results with FE results for varying imperfection amplitude $\omega_{0}$

\begin{tabular}{|c|c|c|c|c|}
\hline \multirow{2}{*}{ Beams } & \multicolumn{4}{|c|}{ FE $\mathrm{M}_{\mathrm{u}} /$ Test $\mathrm{M}_{\mathrm{u}}$} \\
\hline & $\omega_{0}=\mathrm{t} / 10$ & $\omega_{0}=\mathrm{t} / 100$ & $\omega_{0}=\mathrm{t} / 500$ & Measured $\omega_{0}$ \\
\hline $400 \times 200 \times 8.0-B 1$ & 1.10 & 1.13 & 1.14 & 1.12 \\
\hline $400 \times 200 \times 10.0-B 1$ & 1.03 & 1.05 & 1.05 & 1.02 \\
\hline $400 \times 200 \times 12.5-B 1$ & 0.99 & 1.01 & 1.01 & 0.94 \\
\hline $400 \times 200 \times 14.0-B 1$ & 0.98 & 0.99 & 0.99 & 0.92 \\
\hline $400 \times 200 \times 16.0-B 1 a$ & 1.05 & 1.07 & 1.07 & 1.06 \\
\hline $400 \times 200 \times 16.0-B 1 b$ & 1.01 & 1.03 & 1.03 & 1.02 \\
\hline $500 \times 250 \times 8.0-B 1$ & 1.03 & 1.07 & 1.07 & 0.97 \\
\hline $400 \times 200 \times 12.5-B 2$ & 1.05 & 1.05 & 1.05 & 1.05 \\
\hline $400 \times 200 \times 14.0-B 2$ & 1.06 & 1.06 & 1.06 & 1.06 \\
\hline $500 \times 250 \times 8.0-B 2$ & 1.03 & 1.04 & 1.04 & 1.04 \\
\hline $400 \times 200 \times 10.0-B 3$ & 1.02 & 1.04 & 1.05 & 0.96 \\
\hline $400 \times 200 \times 12.5-B 3$ & 0.94 & 1.02 & 1.02 & 0.95 \\
\hline $400 \times 200 \times 14.0-B 3$ & 0.97 & 1.07 & 1.08 & 1.00 \\
\hline $400 \times 200 \times 16.0-B 3$ & 0.98 & 1.08 & 1.10 & 1.00 \\
\hline $400 \times 200 \times 10.0-B 4$ & 0.90 & 0.91 & 0.91 & 0.87 \\
\hline $400 \times 200 \times 12.5-B 4$ & 0.91 & 0.94 & 0.94 & 0.88 \\
\hline $400 \times 200 \times 14.0-B 4$ & 0.98 & 1.02 & 1.02 & 0.99 \\
\hline $400 \times 200 \times 16.0-B 4^{\#}$ & 0.99 & 1.04 & 1.04 & 1.01 \\
\hline MEAN $\mathbf{N}^{\#}$ & 1.00 & 1.03 & 1.04 & 0.99 \\
\hline $\mathbf{C O V}^{\# \#}$ & 0.05 & 0.05 & 0.05 & 0.07 \\
\hline
\end{tabular}

\# test did not reach the peak load

\#\# test results that did not reach peak load not included 